\title{
The North Pacific Acoustic Laboratory deep-water acoustic propagation experiments in the Philippine Sea
}

\author{
Peter F. Worcester ${ }^{a)}$ and Matthew A. Dzieciuch \\ Scripps Institution of Oceanography, University of California at San Diego, La Jolla, California 92093-0225 \\ James A. Mercer, Rex K. Andrew, and Brian D. Dushaw \\ Applied Physics Laboratory, University of Washington, Seattle, Washington 98105 \\ Arthur B. Baggeroer \\ Massachusetts Institute of Technology, Cambridge, Massachusetts 02139 \\ Kevin D. Heaney \\ OASIS, Inc., 11006 Clara Barton Drive, Fairfax Station, Virginia 22039
}

Gerald L. D'Spain

Marine Physical Laboratory, Scripps Institution of Oceanography, University of California at San Diego, La Jolla, California 92093-0701

John A. Colosi

Naval Postgraduate School, Monterey, California 93943

Ralph A. Stephen and John N. Kemp

Woods Hole Oceanographic Institution, Woods Hole, Massachusetts 02543

Bruce M. Howe and Lora J. Van Uffelen

University of Hawaii at Manoa, Honolulu, Hawaii 96822

Kathleen E. Wage

George Mason University, Fairfax, Virginia 22030

(Received 21 April 2013; revised 11 July 2013; accepted 29 July 2013)

A series of experiments conducted in the Philippine Sea during 2009-2011 investigated deep-water acoustic propagation and ambient noise in this oceanographically and geologically complex region: (i) the 2009 North Pacific Acoustic Laboratory (NPAL) Pilot Study/Engineering Test, (ii) the 2010-2011 NPAL Philippine Sea Experiment, and (iii) the Ocean Bottom Seismometer Augmentation of the 2010-2011 NPAL Philippine Sea Experiment. The experimental goals included (a) understanding the impacts of fronts, eddies, and internal tides on acoustic propagation, (b) determining whether acoustic methods, together with other measurements and ocean modeling, can yield estimates of the time-evolving ocean state useful for making improved acoustic predictions, (c) improving our understanding of the physics of scattering by internal waves and spice, (d) characterizing the depth dependence and temporal variability of ambient noise, and (e) understanding the relationship between the acoustic field in the water column and the seismic field in the seafloor. In these experiments, moored and ship-suspended low-frequency acoustic sources transmitted to a newly developed distributed vertical line array receiver capable of spanning the water column in the deep ocean. The acoustic transmissions and ambient noise were also recorded by a towed hydrophone array, by acoustic Seagliders, and by ocean bottom seismometers.

(C) 2013 Acoustical Society of America. [http://dx.doi.org/10.1121/1.4818887]

PACS number(s): 43.30.Re, 43.30.Nb, 43.30.Ma, 43.30.Pc [TFD]

Pages: $3359-3375$

\section{INTRODUCTION}

A series of deep-water acoustic propagation experiments combining low-frequency, broadband sources with vertical and horizontal receiving arrays were conducted in the North Pacific Ocean during the period 1989 to 2005 as part of what is loosely referred to as the North Pacific Acoustic Laboratory (NPAL) (Worcester and Spindel, 2005). These

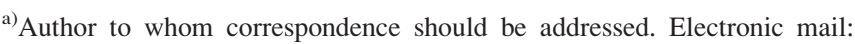
pworcester@ucsd.edu
}

past experiments were designed to measure the spatial and temporal statistics of the fluctuations of resolved rays and acoustic normal modes. The results reflect the background sound-speed field, the relatively low level of eddy variability, the small-scale sound-speed fluctuations caused by internal waves and density-compensated temperature and salinity variations (spice), and the noise sources found in the relatively benign northeast and north central Pacific Ocean.

During 2009-2011, the methods developed to study long-range, deep-water broadband acoustic propagation in the 
central and eastern North Pacific were applied to investigate deep-water acoustic propagation and ambient noise in the much more oceanographically and geologically complex northern Philippine Sea. Three experiments were conducted: (a) the 2009 NPAL Pilot Study/Engineering Test (PhilSea09), (b) the 2010-2011 NPAL Philippine Sea Experiment (PhilSea10), and (c) the Ocean Bottom Seismometer Augmentation of the 2010-2011 NPAL Philippine Sea Experiment (OBSAPS). This paper serves as an introduction to these experiments and presents selected results from each.

In contrast to the oceanographically benign northeast and north central Pacific Ocean, the sound-speed field in the Philippine Sea is modulated by strong eddies that sweep across the basin from the east (Qiu, 1999; Kobashi and Kawamura, 2002; Qiu and Chen, 2010). The westwardpropagating eddies interact with an intense western boundary current, the Kuroshio, that flows northward to the east of Taiwan. Large internal tides generated in Luzon Strait between Taiwan and the Philippines and at the Mariana Island Arc to the east propagate into the region (Niwa and Hibiya, 2004; Jan et al., 2008; Zhao and D'Asaro, 2011; Kerry et al., 2013). Typhoons regularly cross the Philippine Sea during summer and fall affecting the structure of the upper ocean.

Even in deep water, sound that interacts with the seafloor contributes significantly to the received signal at short ranges. The bathymetry in the Philippine Sea is the result of complicated tectonic processes with islands and straits to the west and rugged topography in the interior. Seafloor properties such as sediment thickness, sound speed, and density differ dramatically from those in the north central and northeast Pacific, with a considerable amount of volcaniclastic debris and turbidites (Karig, 1975; Salisbury et al., 2006).

A number of major shipping routes traverse the Philippine Sea. The shipping density in the region is much higher than in the central North Pacific with implications for the low-frequency ambient noise field.

The goals of the Philippine Sea experiments included (1) understanding the impacts of fronts, eddies, and internal tides on acoustic propagation, (2) determining whether acoustic methods, together with other measurements and ocean modeling, can yield estimates of the time-evolving ocean state useful for making improved acoustic predictions and for understanding the local ocean dynamics, (3) improving our understanding of the physics of scattering by internal waves and spice, (4) characterizing the depth dependence and temporal variability of the ambient noise field, and (5) understanding the relationship between the acoustic field in the water column and the seismic field in the seafloor for both ambient noise and signals.

Section II provides brief summaries of the physical oceanography, geology, and acoustic properties of the Philippine Sea. The next three sections provide overviews of the three experiments and present selected results from each. Some concluding remarks are made in Sec. VI. The Appendix provides a brief description of a newly developed distributed vertical line array (DVLA) receiver capable of spanning the water column in the deep ocean that was used in various configurations in all three experiments.

\section{PHILIPPINE SEA ENVIRONMENT}

The physical oceanography and marine geology of the Philippine Sea, both of which affect acoustic propagation, are briefly summarized in the following text. A discussion of the acoustic environment, including sound-speed profiles and ambient noise, follows.

\section{A. Physical oceanography}

The circulation in the interior of the northern Philippine Sea is dominated by the broad, wind-driven, westward-flowing North Equatorial Current (NEC), which is subsurface in this region, and the relatively shallow and weak eastwardflowing North Pacific Subtropical Countercurrent (STCC) at $18^{\circ}-25^{\circ} \mathrm{N}$, between the midlatitude westerly winds and the low-latitude trade winds (Qiu and Chen, 2010). The intensity of the STCC peaks in the spring and is at a minimum in the fall. In the western Philippine Sea, a strong western boundary current, the Kuroshio, flows northward immediately to the east of Taiwan. The NEC supplies the region with two distinct water masses marked by salinity extrema (Rudnick et al., 2011). North Pacific Tropical Water (NPTW) is marked by high salinity near 200-m depth; North Pacific Intermediate Water (NPIW) is associated with a salinity minimum near 500-m depth (Figs. 1 and 2).

A zonal band of strongly enhanced eddy activity centered at about $22^{\circ} \mathrm{N}$ and extending east to $180^{\circ}$ is associated with the STCC (Qiu, 1999; Kobashi and Kawamura, 2002; Qiu and Chen, 2010). In the entire North Pacific, only the mesoscale eddies in the Kuroshio Extension east of Japan are stronger than those to the east of Taiwan. In the Philippine Sea, the currents associated with the mesoscale eddies are far stronger than the mean currents associated with the NEC and the STCC. The temperature anomalies
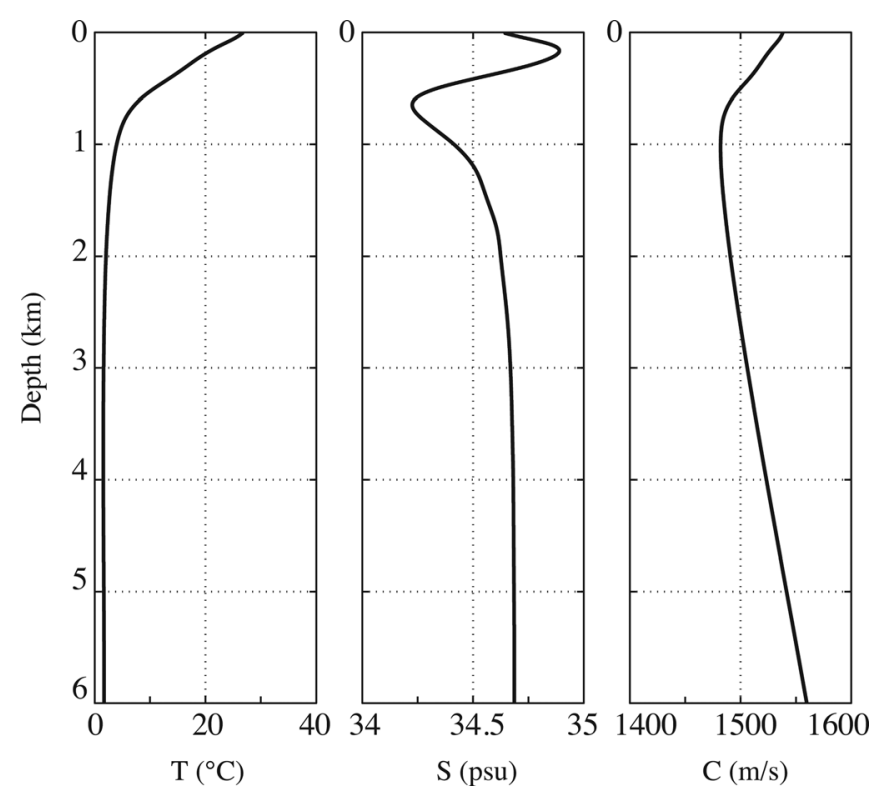

FIG. 1. Annual average temperature, salinity and sound-speed profiles at $21.36^{\circ} \mathrm{N}, 126.02^{\circ} \mathrm{E}$, approximately at the locations of the PhilSea09 and PhilSea10 DVLAs, as derived from the World Ocean Atlas 2005 (Antonov et al., 2006; Locarnini et al., 2006). 


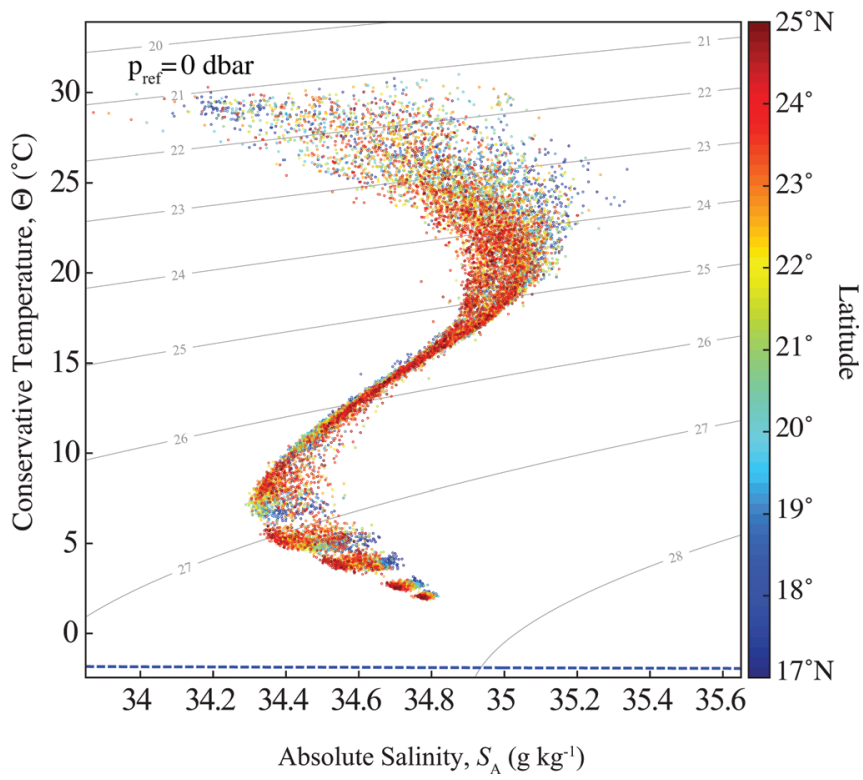

FIG. 2. Conservative temperature vs absolute salinity (IOC et al., 2010) for the upper $2000 \mathrm{~m}$ in the central Philippine Sea $\left(17^{\circ}-25^{\circ} \mathrm{N}, 122^{\circ}-132^{\circ} \mathrm{E}\right)$ derived from profiling float measurements made from 2004 through 2011. The data points are colored to indicate the latitude $(\mathrm{N})$ at which they were acquired. The dashed blue line is the freezing point of seawater. These data were collected and made freely available by the International Argo Program and the national programs that contribute to it (http://www.argo.ucsd.edu, http://argo.jcommops.org). The Argo Program is part of the Global Ocean Observing System. (B. Cornuelle, personal communication.)

associated with the eddies extend as deep as $1000 \mathrm{~m}$. The dominant eddy time scale is $\sim 100$ days (Qiu and Chen, 2010). The eddy kinetic energy (EKE) level within the STCC band has a well-defined annual cycle with a maximum in April/May and a minimum in December/January. In addition to its seasonal modulation, the EKE also varies on interannual time scales.

The dominant water masses intruding into the region, NPTW and NPIW, are stirred by the strong eddy field, leading to fluctuations in temperature and salinity along isopycnals (Rudnick et al., 2011). Layers of strong spice variability therefore occur at the depths of the salinity maximum associated with the NPTW and to a lesser extent at the salinity minimum associated with the NPIW. The variability in the temperature-salinity relationship at the locations of the salinity extrema in Fig. 2 is a reflection of the strong spice variability at the depths of these water masses (see also Fig. 3 in Colosi et al., 2013). Between the salinity extrema is a layer of weak spice variability that is reflected in the tightness of the temperature-salinity relationship near $15^{\circ} \mathrm{C}$. Spice is quite inhomogeneous in space and intermittent in time (Rudnick et al., 2011; Colosi et al., 2013).

Tidal variability in the Philippine Sea includes both the barotropic tide and large baroclinic tides generated in the Luzon Strait to the west and the Mariana Island Arc to the east. The baroclinic semi-diurnal and diurnal displacements are of roughly the same magnitude and are a significant component of the overall variability (Colosi et al., 2013). There is considerable variability in estimates of the baroclinic $\mathrm{M}_{2}$ energy flux into the Philippine Sea. Niwa and Hibiya (2004) estimate from a three-dimensional model simulation that

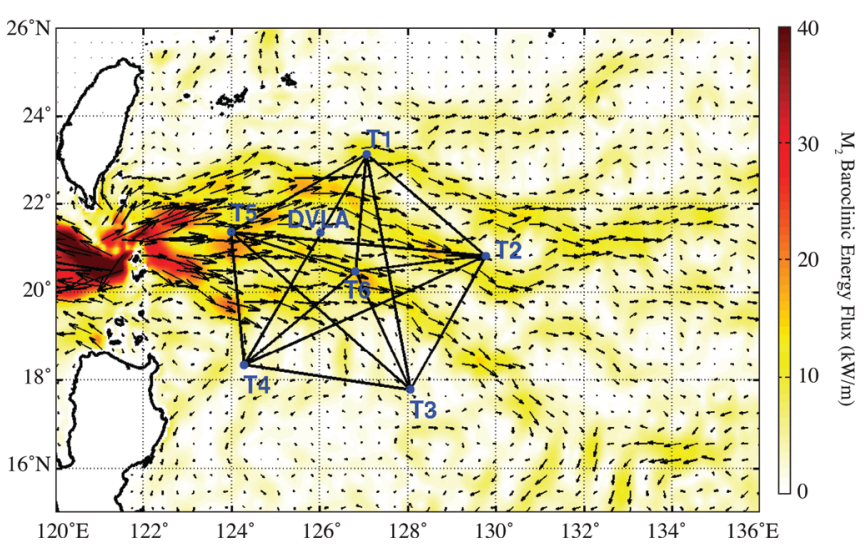

FIG. 3. Modeled vertically integrated baroclinic $\mathrm{M}_{2}$ energy fluxes in the Philippine Sea (Kerry et al., 2013; Powell et al., 2013), together with the PhilSea10 mooring locations.

$14 \mathrm{GW}$ of energy in the $\mathrm{M}_{2}$ barotropic tide is converted into the baroclinic tide at Luzon Strait with $3.2 \mathrm{GW}$ propagating into the Philippine Sea. Jan et al. (2008) simulated the internal tide generation in the Luzon Strait for the four principal constituents $\left(\mathrm{O}_{1}, \mathrm{~K}_{1}, \mathrm{M}_{2}, \mathrm{~S}_{2}\right)$. They found that barotropic to baroclinic energy conversion for the $\mathrm{M}_{2}$ tide was $9.6 \mathrm{GW}$ with $2.3 \mathrm{GW}$ propagating eastward. Most recently, Kerry et al. (2013) and Powell et al. (2013), using the regional ocean modeling system (ROMS), found that $17 \mathrm{GW}$ of $\mathrm{M}_{2}$ barotropic tidal energy is converted into internal tides in the Luzon Strait with $4.8 \mathrm{GW}$ propagating eastward into the Philippine Sea (Fig. 3). Zhao and D'Asaro (2011) find from altimetric data and air-launched expendable bathythermographs (AXBTs) that westward-propagating $\mathrm{M}_{2}$ internal tides generated at the Mariana Arc converge in a focal region centered at $17^{\circ} \mathrm{N}, 139.6^{\circ} \mathrm{E}$, well to the east of the region of interest here, and then diverge as they propagate west beyond the focus.

Strongly nonlinear internal solitons that are generated in Luzon Strait at tidal intervals and propagate westward occur regularly in the South China Sea (e.g., Ramp et al., 2004). In contrast, internal solitons seem to be uncommon in the northern Philippine Sea, although at least one has been detected (Chu and Hzieh, 2007). Nonetheless, the internal tide in the Philippine Sea has a rich harmonic structure (Colosi et al., 2013), which is indicative of nonlinear wave propagation.

Finally, the random internal gravity wave field below the mixed layer in the Philippine Sea is, not surprisingly, relatively well described by the model spectrum developed by Garrett and Munk (Munk, 1981) except that the internal wave energy level seems to be somewhat elevated (Colosi et al., 2013).

The temperature, salinity, and velocity structure in the Philippine Sea were measured during the NPAL Philippine Sea experiments using a combination of moored sensors and conductivity-temperature-depth (CTD) profiles (Colosi et al., 2013). Temperature and salinity measurements in the upper $1000 \mathrm{~m}$ were also collected by Seagliders transiting between the moorings during PhilSea10 (Howe et al., 2011; Van Uffelen et al., 2013). 


\section{B. Marine geology}

Unlike broad sections of the North Pacific, the western Philippine Sea was formed by seafloor spreading in a backarc basin, resulting in complex seafloor topography and structure (Karig, 1975; Louden, 1977; Matsubara and Seno, 1980; Seno and Maruyama, 1984; Goodman et al., 1989; Salisbury et al., 2006). Multibeam bathymetric data obtained during the NPAL Philippine Sea experiments were combined with other available multibeam data and Global Topography V14.1 (Smith and Sandwell, 1997) to generate a highresolution bathymetric map of the region (Fig. 4).

The Philippine Sea is surrounded by volcanoes, resulting in a sediment layer that includes a considerable amount of volcaniclastic debris and turbidites (Salisbury et al., 2006). The most accurate estimates of sediment thickness are obtained by drilling. Although the Deep Sea Drilling Project (DSDP) and Ocean Drilling Project (ODP) did not drill sites within the NPAL experimental area, many features of seafloor structure are a function of plate age (Houtz and Ewing, 1976). Sites 290, 293, and 1201 with crustal ages of 45-50 Ma are therefore expected to have properties similar to those in the experimental area, which has ages of 37-50 Ma, even though they are in some cases considerable distances from it (Fig. 4). The drilled sediment thicknesses at Sites 293 and 1201 were 563 and $510 \mathrm{~m}$, respectively. (Site 290 had not reached basement at $255 \mathrm{~m}$.) Some idea of the variability in sediment thickness can be obtained from Karig (1975) based on seismic reflection data. The southwestern section of the experimental area has relatively thick sediments, $340-500 \mathrm{~m}$. The northeastern section is a region of "irregular topography and variable sediment thickness" with a qualitative average thickness between 170 and $340 \mathrm{~m}$.

Tables of sonic velocities made on cored material are available for Sites 290, 293, and 1201 (Shipboard Scientific Party, 1975a,b, 2002). Site 1201 also has in situ sonic velocity data. There is considerable scatter, with values from

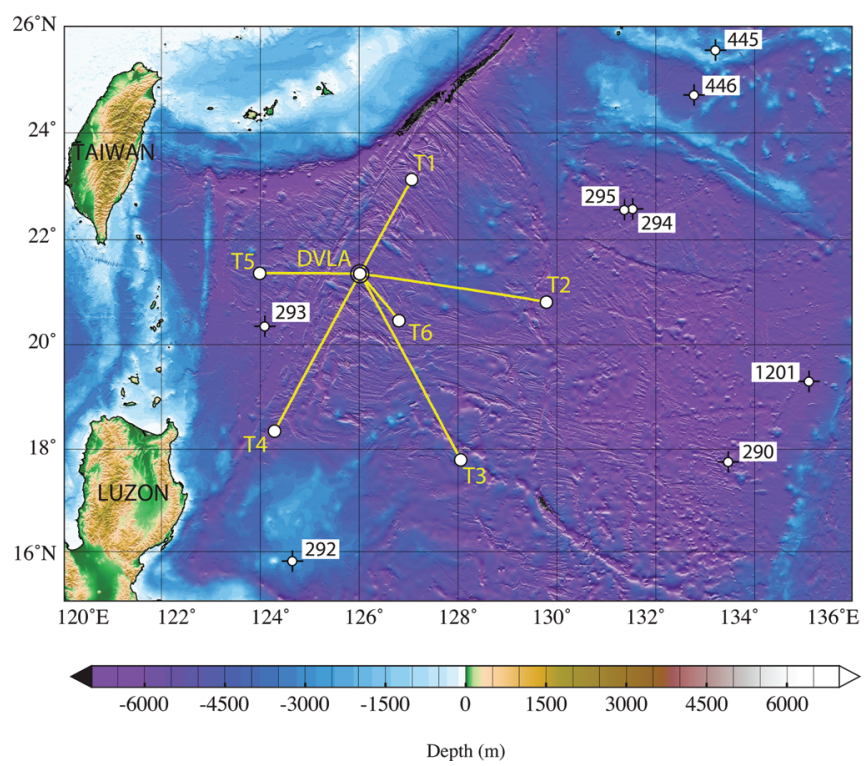

FIG. 4. Seafloor topography in the western Philippine Sea together with the PhilSea10 mooring locations and DSDP and ODP drill site locations. about 1.7 to $3.8 \mathrm{~km} / \mathrm{s}$. Two core sample speeds at Site 290 from around $250-\mathrm{m}$ depth exceed $4.0 \mathrm{~km} / \mathrm{s}$, and one sample exceeds $5.0 \mathrm{~km} / \mathrm{s}$. With so much scatter, it is difficult to give a representative sound speed for the sediment layer. The sonic velocity logging data at Site 1201 give an interval velocity for the whole sediment layer of $2.25 \mathrm{~km} / \mathrm{s}$ (Fig. F16 in Shipboard Scientific Party, 2002).

In summary, the sediments in the western Philippine Sea are much thicker ( $\sim 500 \mathrm{~m}$ vs less than $50 \mathrm{~m})$ and have higher compressional speeds ( $2.25 \mathrm{vs} 1.6 \mathrm{~km} / \mathrm{s}$, typical of pelagic ooze) than open-ocean sites of similar age, for example, off the East Pacific Rise. No direct measurements of sediment properties were made during the NPAL Philippine Sea experiments, however.

\section{Acoustics}

The sound-speed profile in the northern Philippine Sea is a typical temperate profile with the sound-channel axis at a depth of 1000-1100m (Fig. 1). Most locations are sufficiently deep that the surface conjugate depth (i.e., critical depth) is located above the seafloor throughout the year (Fig. 5). Long-range acoustic propagation is therefore typically surface limited.

A number of shipping lanes traverse the Philippine Sea (Fig. 6) with implications for the low-frequency ambient noise field. Particularly heavily trafficked shipping lanes pass to the east of Taiwan (west of the NPAL experimental area) and to the north of Taiwan and through the Ryukyu Islands (north of the NPAL experimental area). Evans and Carey (2009) calculated the vertical and horizontal directivity of underwater noise in the Philippine Sea based on a combination of historical shipping densities and observed wind speeds.

Ambient noise measurements were made above and below the surface conjugate depth in the Philippine Sea in the late 1970s and 1980s using analog recording systems. The Applied Research Laboratories of The University of Texas at Austin measured ambient noise levels in 2007 near

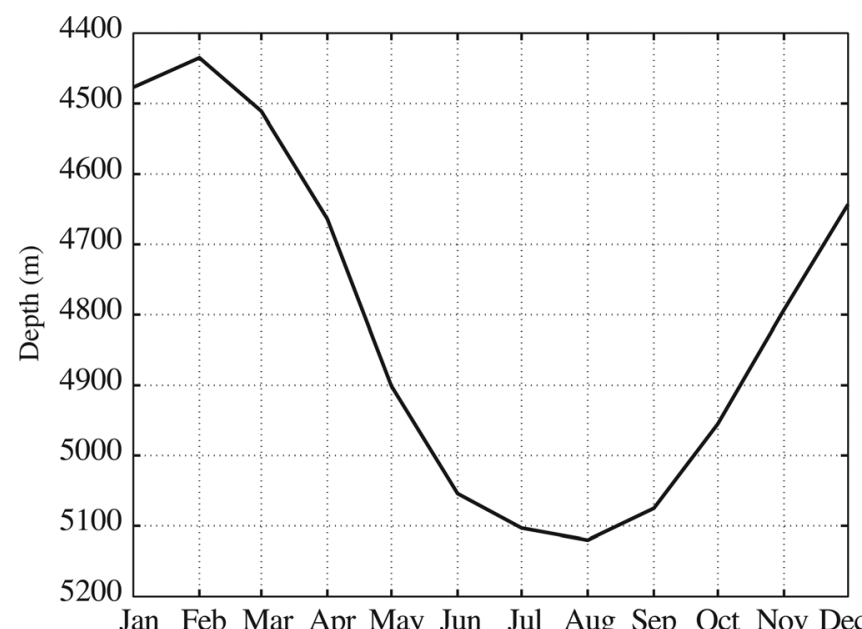

FIG. 5. Surface conjugate depths throughout the year at $21.36^{\circ} \mathrm{N}, 126.02^{\circ} \mathrm{E}$, approximately at the locations of the PhilSea09 and PhilSea10 DVLAs, as derived from the World Ocean Atlas 2005 (Antonov et al., 2006; Locarnini et al., 2006). 


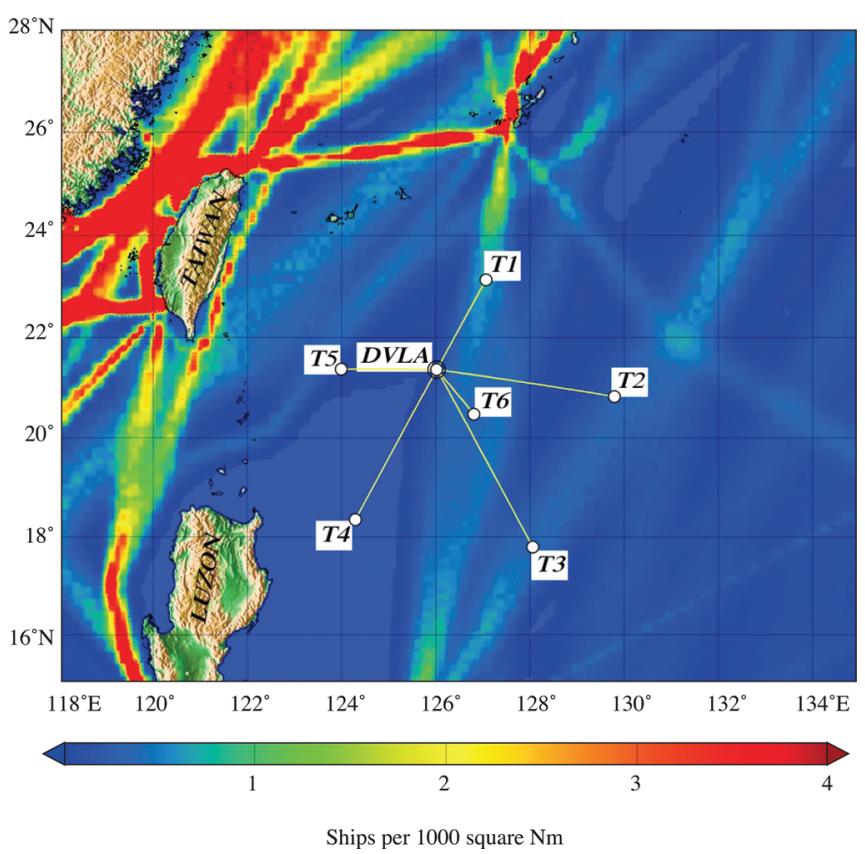

FIG. 6. Shipping density in the Philippine Sea in ships per $1000 \mathrm{~nm}^{2}$ for supertankers, large tankers, tankers, and merchant ships combined as derived from the Historical Temporal Shipping (HITS) database (Emery et al., 2001).

one of the locations previously occupied in 1987 (D. Knobles, personal communication). In both the old and 2007 measurements, the omnidirectional noise level at $50 \mathrm{~Hz}$ was approximately $75 \mathrm{~dB}$ re $1 \mu \mathrm{Pa}^{2} / \mathrm{Hz}$ above the surface conjugate depth. The noise level was about $67 \mathrm{~dB}$ re $1 \mu \mathrm{Pa}^{2} / \mathrm{Hz}$ well below the surface conjugate depth on hydrophones $20-30 \mathrm{~m}$ above the seafloor, a reduction of about $8 \mathrm{~dB}$. In contrast, in the northeast Pacific Ocean the omnidirectional noise level decreases as much as $20-25 \mathrm{~dB}$ between the surface conjugate depth and the seafloor (Shooter et al., 1990; Gaul et al., 2007).

\section{2009 NPAL PILOT STUDY/ENGINEERING TEST (PhilSea09)}

A short-term pilot study/engineering test was conducted in the Philippine Sea during April-May 2009. The objectives were to (1) obtain an initial look at deep-water acoustic propagation and ambient noise in the northern Philippine Sea, (2) study short-term temporal variability using long-duration acoustic transmissions, and (3) test the equipment planned for use in 2010-2011 under actual operating conditions.

\section{A. Experiment}

A single acoustic path, approximately corresponding to one of those to be instrumented during the 2010-2011 PhilSea10 experiment, was instrumented with a moored, broadband source (T1) and a prototype DVLA receiver (Fig. 7). Both moorings remained in place for about one month, while coordinated, ship-based measurements were made. These included transmissions to the DVLA from sources suspended from shipboard and recording of the T1 and ship-suspended source transmissions by the towed Five Octave Research Array (FORA) (Becker and Preston, 2003).

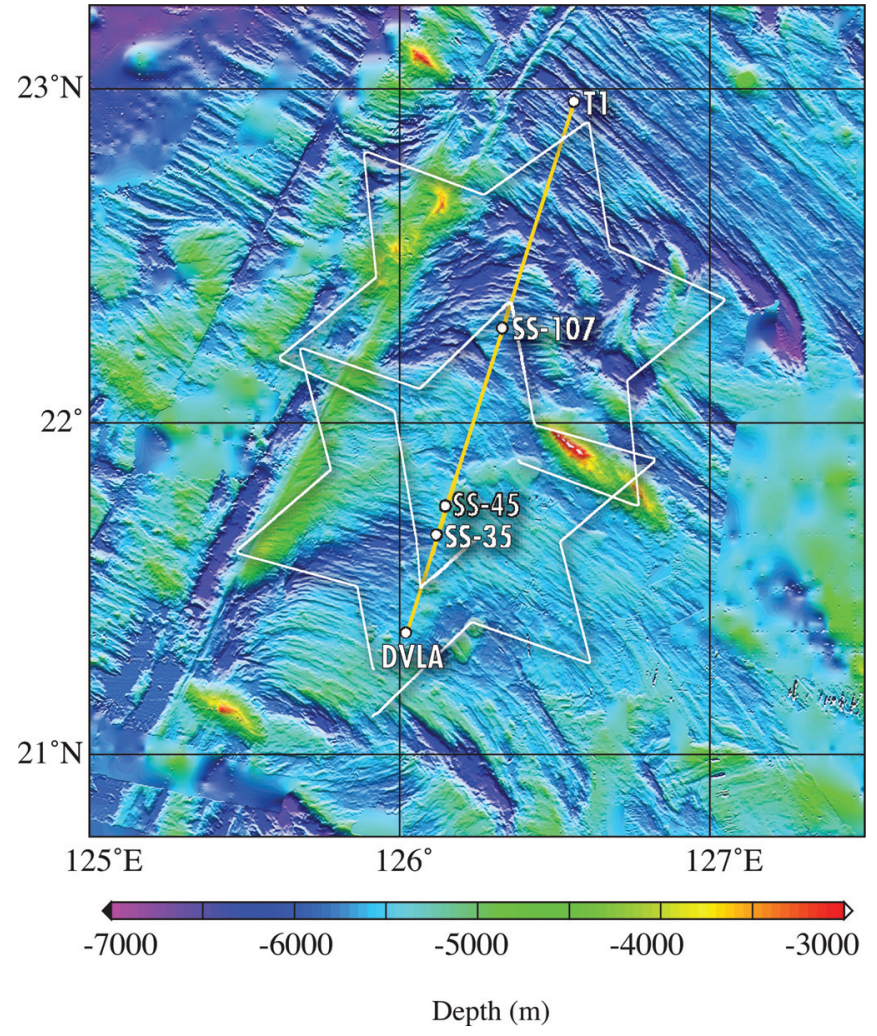

FIG. 7. Geometry of the PhilSea09 experiment. A broadband acoustic source was moored at T1. A prototype distributed vertical line array receiver was moored at DVLA. Sources were suspended from shipboard for varying durations at ship stations SS-35, SS-45, and SS-107. The FORA horizontal array was towed in Star-of-David patterns around SS-45 and SS-107 while recording the acoustic transmissions made at those locations. A J15-3 source suspended from shipboard and the FORA horizontal array also executed a number of additional maneuvers (not shown).

Table I gives the nominal mooring and ship station locations. The range (WGS84) from the reference position of the DVLA to the reference position of mooring T1 was $185.127 \mathrm{~km}$.

\section{Moored transceiver}

The moored source was a Teledyne Webb Research swept-frequency acoustic source (S/N 1) that transmitted linear frequency-modulated (LFM) signals extending from 225 to $325 \mathrm{~Hz}$ and lasting $135 \mathrm{~s}$ (Webb et al., 2002; Morozov and Webb, 2003, 2007). The source was calibrated at Seneca Lake Sonar Test Facility following the experiment. The maximum source level was $184.9 \mathrm{~dB}$ re $1 \mu \mathrm{Pa}$ at $1 \mathrm{~m} \mathrm{rms}$, and the average transmitted power level over the full bandwidth was approximately $181.9 \mathrm{~dB}$ re $1 \mu \mathrm{Pa}$ at $1 \mathrm{~m} \mathrm{rms}$. The transmitted waveform deviated from an ideal linear FM signal, and the actual measured waveform was therefore used to construct the reference signal for pulse compression. The source transmitted every $3 \mathrm{~h}$, except for one 72 -h period and two additional 24-h periods when it transmitted at 5-min intervals. The 3 -h sampling interval is adequate to resolve the semi-diurnal tides. The 5-min sampling interval was designed to explore short-period acoustic fluctuations.

The median source depth was $1098.6 \mathrm{~m}$. This depth was used as the reference depth when correcting for mooring motion. An array of four hydrophones spaced $9.0 \mathrm{~m}$ apart 
TABLE I. Nominal locations of the moorings and ship stations during PhilSea09. Water depths are corrected depths.

\begin{tabular}{lcc}
\hline \hline & \multicolumn{1}{c}{ Location } & Source depth (m) \\
\hline DVLA & $21^{\circ} 22.0979^{\prime} \mathrm{N}, 126^{\circ} 1.2033^{\prime} \mathrm{E}$ & 5530 \\
T1 & $22^{\circ} 57.7118^{\prime} \mathrm{N}, 126^{\circ} 33.7706^{\prime} \mathrm{E}$ & 1098.6 \\
SS-35 & $21^{\circ} 39.8950^{\prime} \mathrm{N}, 126^{\circ} 07.1120^{\prime} \mathrm{E}$ & $\mathrm{J} 15-3: 15 / 60$ \\
SS-45 & $21^{\circ} 45.0500^{\prime} \mathrm{N}, 126^{\circ} 08.8834^{\prime} \mathrm{E}$ & $\mathrm{J} 15-3: 15 / 60$ \\
SS-107 & $22^{\circ} 16.9500^{\prime} \mathrm{N}, 126^{\circ} 19.7667^{\prime} \mathrm{E}$ & $\mathrm{J} 15-3: 15 / 60 \mathrm{MP}-200: 1000$ \\
\hline \hline
\end{tabular}

(approximately $3 / 2 \lambda$ at $250 \mathrm{~Hz}$ ) was located above the source to record ambient noise. A long-baseline acoustic navigation system with three acoustic transponders on the seafloor was used to determine the source position once per hour throughout the experiment.

\section{Prototype DVLA}

The DVLA consisted of two 1000-m subarrays: An axial subarray spanning the sound-channel axis and a deep subarray spanning the surface conjugate depth. A distributed vertical line array-simple tomographic acoustic receiver (D-STAR) controller located at the top of each subarray provided timing and scheduling for distributed, self-recording hydrophone modules that were clamped to the mooring wire (Appendix). Inductively coupled modems provided low-bandwidth (1200 baud) communication between the D-STAR controllers and the hydrophone modules over standard oceanographic mooring wire for command, control, and time synchronization.

Each subarray contained 30 hydrophone modules (Table II). The axial subarray was configured with (1) an array of 25 hydrophone modules spaced $25 \mathrm{~m}$ apart to resolve loworder modes, (2) two (2) hydrophone modules spaced $75 \mathrm{~m}$ apart above the mode-resolving array, and (3) three (3) hydrophone modules spaced $75 \mathrm{~m}$ apart below the moderesolving array. The more widely spaced hydrophone modules were designed to characterize the near-axial time front. The deep subarray was configured with (1) a dense array of 20 hydrophone modules spaced $5 \mathrm{~m}$ apart (approximately $\lambda / 2$ at $150 \mathrm{~Hz}$ ) to resolve the angular dependence of the ambient noise below the surface conjugate depth and (2) ten (10) hydrophone modules spaced $90 \mathrm{~m}$ apart located above the dense array to characterize the time front and ambient noise in the vicinity of the surface conjugate depth. A longbaseline acoustic navigation system with four acoustic transponders on the seafloor was used to determine the array position and shape once per hour throughout the experiment.

TABLE II. Nominal hydrophone module depths and spacing in the PhilSea09 DVLA.

\begin{tabular}{lrcc}
\hline \hline DVLA subarray & Depths $(\mathrm{m})$ & Spacing $(\mathrm{m})$ & Number of modules \\
\hline Axial & $650-725$ & 75 & 2 \\
& $800-1400$ & 25 & 25 \\
& $1475-1625$ & 75 & 3 \\
Deep & $4285-5095$ & 90 & 10 \\
& $5185-5280$ & 5 & 20 \\
\hline \hline
\end{tabular}

The DVLA recorded for $155 \mathrm{~s}$ beginning $10 \mathrm{~s}$ prior to the nominal arrival time of the $\mathrm{T} 1$ transmissions to provide approximately10-s buffer periods before and after the receptions. In addition, during the times that the T1 source was transmitting every $3 \mathrm{~h}$, the DVLA recorded ambient noise for $155 \mathrm{~s}$ shortly after each T1 reception. Finally, the DVLA recorded continuously at times when the ship-suspended sources were scheduled to be transmitting, except for intervals once per hour to allow the long-baseline navigation system to measure the mooring motion. The sample rate for all acoustic receptions was $1953.125 \mathrm{~Hz}$.

\section{Ship-suspended sources}

The ship-suspended sources included J15-3 and MP-200 Multiport sources suspended from the $R / V$ Melville. The J15-3 and MP-200 source transmissions were recorded by both the DVLA and the FORA horizontal array.

The $\mathrm{J} 15-3$ projector is a standard transducer provided by the Underwater Sound Reference Division of the Naval Undersea Warfare Center (Groves, 1974; Young, 1975). It transmitted a combination of continuous wave $(\mathrm{CW})$ and linear FM signals at ship stations SS-35, SS-45, and SS-107 as well as during a number of tows (Fig. 7). The source was deployed at nominal depths of 15 or $60 \mathrm{~m}$ during these events. The maximum $\mathrm{J} 15-3$ source level is $180 \mathrm{~dB}$ re $1 \mu \mathrm{Pa}$ at $1 \mathrm{~m} \mathrm{rms}$, although the transmitted levels were all less than this in order to avoid signal distortion.

The MP-200 Multiport source is an experimental, doubleported doubly resonant device designed by ImageAcoustics, Inc., and manufactured by Massa Products, Inc. (Andrew, 2009). At ship station SS-107, the MP-200 transmitted a phase-coded, periodic $m$-sequence with a carrier frequency of $284.1666 \mathrm{~Hz}$ (Table III) (Munk et al., 1995). An equalization correction was applied to the drive signal ("pre-equalizer") to compensate for the doubly resonant response of the source. The pre-equalizer did not fully compensate for the system transfer function, and a "post-equalizer" filter was therefore also applied to the received data. The source depth was $1000 \mathrm{~m}$. The source level was approximately $183 \mathrm{~dB}$ re $1 \mu \mathrm{Pa}$ at $1 \mathrm{~m}$ rms. The MP-200 continuous transmissions recorded on the DVLA provide information on the statistics of the acoustic fluctuations caused by internal waves, internal tides, and spice.

\section{Towed hydrophone array}

The FORA horizontal array was towed by the $R / V$ Kilo Moana. The FORA array includes four modules coupled to form a nested set of acoustic apertures with hydrophones spaced $\lambda / 2$ apart at frequencies of 250, 500, 1000, and 
TABLE III. Parameters of the periodic phase-coded $m$-sequence signals transmitted by the MP-200 and HX-554 sources during PhilSea09 and PhilSea10. The HX-554 transmitted different signals at depths of 150 and $998 \mathrm{~m}$. The periodic $m$-sequence signals summed to construct the composite signal used to drive the MP-200 during PhilSea10 are labeled "Red" and "Violet."

\begin{tabular}{|c|c|c|c|c|c|}
\hline & \multirow{3}{*}{$\frac{\text { PhilSea09 }}{\text { MP-200 }}$} & \multicolumn{4}{|c|}{ PhilSea10 } \\
\hline & & \multicolumn{2}{|c|}{ HX-554 } & \multicolumn{2}{|c|}{ MP-200 } \\
\hline & & $150 \mathrm{~m}$ & $998 \mathrm{~m}$ & Red & Violet \\
\hline Carrier frequency $(\mathrm{Hz})$ & $284.1666 \ldots$ & 61.38 & 81.88 & 200 & 300 \\
\hline Cycles/digit & 2 & 2 & 2 & 4 & 6 \\
\hline Digit length (ms) & 7.0381 & 32.5839 & 24.4260 & 20.0000 & 20.0000 \\
\hline Sequence length (digits) & 1023 & 1023 & 2047 & 1023 & 1023 \\
\hline Sequence period (s) & 7.2000 & $33.3333 \ldots$ & 50.0000 & 20.4600 & 20.4600 \\
\hline Sequence law & $2033_{8}$ & $2033_{8}$ & $4533_{8}$ & $2033_{8}$ & $3471_{8}$ \\
\hline Phase modulation angle & $88.209^{\circ}$ & $88.209^{\circ}$ & $88.734^{\circ}$ & $88.209^{\circ}$ & $88.209^{\circ}$ \\
\hline
\end{tabular}

$2000 \mathrm{~Hz}$ (Becker and Preston, 2003). The overall aperture is $189 \mathrm{~m}$ with 64 channels spaced $\lambda / 2$ apart at $250 \mathrm{~Hz}$. (A connector failure approximately half-way through the PhilSea09 experiment reduced the array to 32 channels.) The array was towed at depths that varied between 120 and $250 \mathrm{~m}$, depending on the event, and a speed of $1.8 \mathrm{~m} / \mathrm{s}(3.5 \mathrm{kn})$. The goals of the FORA measurements were to (1) elucidate convergence zone structure in the complex Philippine Sea environment, including the dependence of convergence zone width on the oceanography, bathymetry, and source depth, (2) study bottom-bounce propagation, including the effects of bathymetric roughness and sediment type, and (3) measure the horizontal structure of the ambient noise field. To study the variability and predictability of the structure of the first convergence zone, the FORA array was towed in "Star-ofDavid" patterns centered on the J15-3 and MP-200 sources suspended from shipboard at SS-45 (J15-3) and SS-107 (J15-3 and MP-200) (Fig. 7). The tracks were designed to cross the first convergence zone multiple times to study the impact of local bathymetry while avoiding placing the sources in the forward endfire beam of the FORA array, which was contaminated by own-ship noise from the $R / V$ Kilo Moana. The ranges to the FORA array from the stationary sources extended from 45 to $70 \mathrm{~km}$. To measure the horizontal structure of the ambient noise, the FORA array was towed in a pentagon (not shown). A number of additional maneuvers were also executed.

\section{Environmental measurements}

The DVLA and T1 moorings were populated with Seabird MicroCATs (SBE 37-SM/SMP) and temperature recorders (SBE 39) at depths spanning nearly the full water column (88-4997 $\mathrm{m}$ for the DVLA and 146-4950 $\mathrm{m}$ for the T1 mooring) (Colosi et al., 2013). The instruments were concentrated above $2000 \mathrm{~m}$, however, at depths derived from WKB baroclinic scaling. They sampled at $60-s$ intervals. In addition, all of the hydrophone modules on the DVLA made precision temperature measurements (Appendix). The sample interval was normally $15 \mathrm{~min}$ but decreased to $5 \mathrm{~min}$ during times that the DVLA was recording continuously.

Near-surface currents were measured using an upwardlooking RDI WHS $150-\mathrm{kHz}$ acoustic Doppler current profiler (ADCP) at about 335-m depth on the DVLA and upward- and downward-looking RDI WHS 300-kHz ADCPs at about 200-m depth on mooring T1. The ADCPs sampled at 20-min intervals. Deep currents at the DVLA were measured using a Nortek 6000-m Aquadopp current meter located $94 \mathrm{~m}$ above the seafloor. It generated a 2-min average at 5min intervals.

Finally, CTD and XBT casts were made in the general vicinities of the DVLA and T1 moorings and along the line between them.

\section{B. Selected results}

Sea-bird SBE37-SMP instruments with pumped conductivity sensors located on the DVLA in the depth range $100-500 \mathrm{~m}$ provided high quality information on potential density and salinity (Fig. 8) (Colosi et al., 2013). The potential density field shows the typical variations associated with random internal waves, but more noticeable are the strong fluctuations at tidal frequencies, particularly the diurnals with periods close to 1 day. The salinity field shows variations similar to those in the density field. However, a significant feature with enhanced salinity in the upper ocean passed by the DVLA between year days 105 and 120. The associated gradients of salinity along isopycnals indicate spice variability. These data, when combined with data from CTD profiles, suggest that stronger spice regions are confined to depths above $200 \mathrm{~m}$ and between 500 and $800 \mathrm{~m}$, consistent with historical information.

The axial and deep subarrays on the DVLA allowed the angular distribution of the ambient noise to be determined at both the sound-channel axis and below the surface conjugate depth, although with differing vertical resolutions because of the difference in element spacing (Fig. 9). To roughly equalize the angular resolutions of the arrays, Fig. 9 shows the vertical noise structure at $50 \mathrm{~Hz}$ for the upper array $\left(3^{\circ}\right.$ angular resolution) and at $150 \mathrm{~Hz}$ for the lower array $\left(6^{\circ}\right.$ angular resolution). The spacing on the upper array $(25 \mathrm{~m})$ exceeds $\lambda / 2$ at $50 \mathrm{~Hz}$, but this does not cause difficulties when steering near broadside (i.e., horizontal). The vertical distribution of the low-frequency ambient noise at the upper array is symmetric about the horizontal and falls off quickly above $\pm 15^{\circ}$, similar to the behavior seen in comparable measurements at other locations and consistent with shipping noise from relatively long ranges. The vertical noise distribution at 


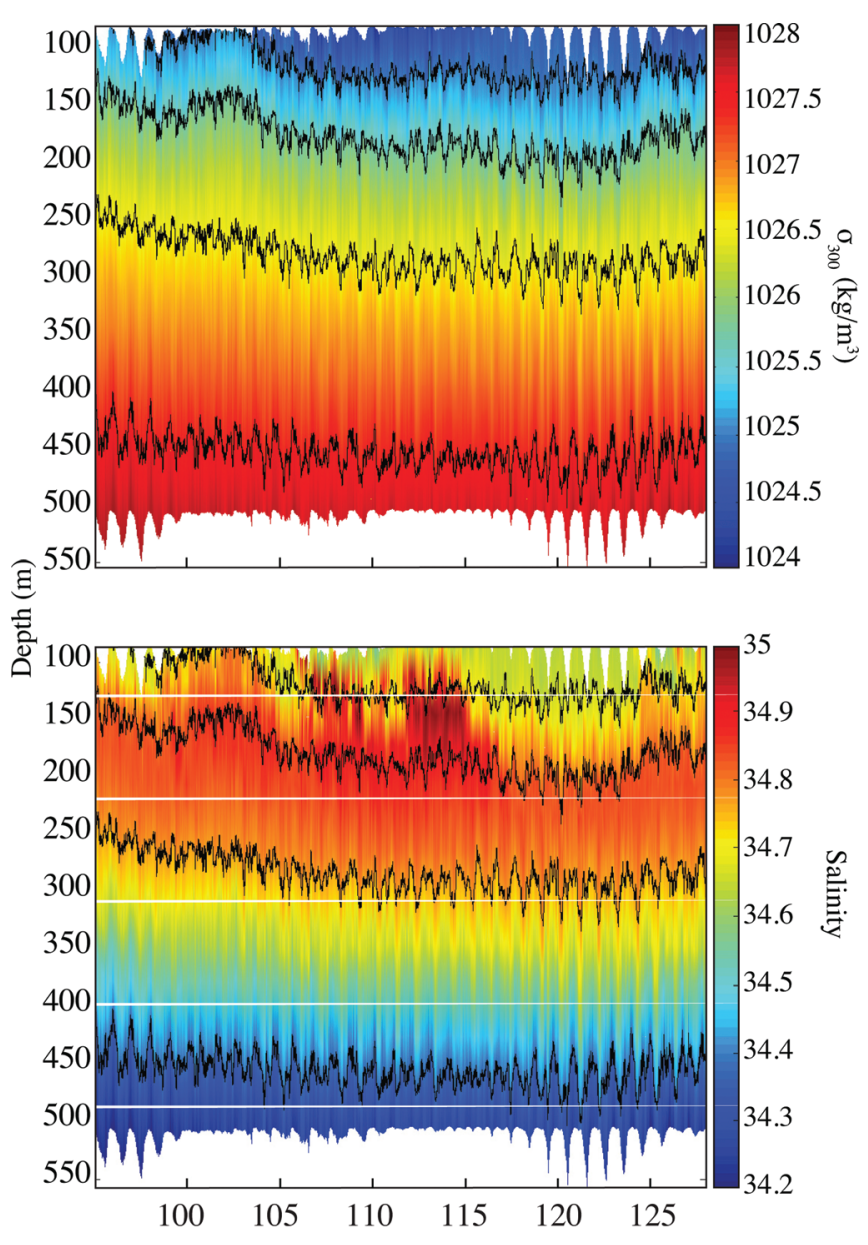

Year day 2009

FIG. 8. Potential density $\sigma_{300}\left(\mathrm{~kg} / \mathrm{m}^{3}\right)$ referenced to $300-\mathrm{m}$ depth (upper) and salinity (lower) at the DVLA during PhilSea09 as a function of depth and time. Superimposed are isopycnal depths for densities of 1025, 1025.7, 1026.5, and $1027.4 \mathrm{~kg} / \mathrm{m}^{3}$. (Reproduced from Colosi et al., 2013.)

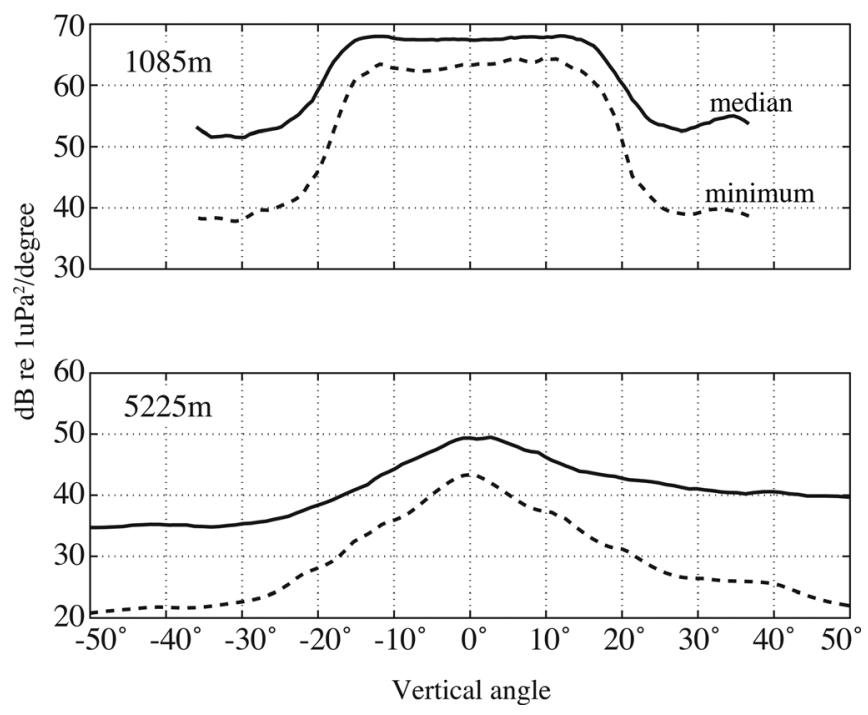

FIG. 9. Vertical ambient noise distributions at $1085 \mathrm{~m}$ depth (near the sound-channel axis) at $50 \mathrm{~Hz}$ and at $5225 \mathrm{~m}$ depth (below the surface conjugate depth) at $150 \mathrm{~Hz}$. The upper (lower) panel has an angular resolution of about $3^{\circ}\left(6^{\circ}\right)$. The median and minimum noise levels over the approximately 1-month duration of PhilSea09 are shown. the lower array is asymmetric about the horizontal with higher levels looking toward the surface. The different structures cannot be explained by differences in array angular resolution alone. Ambient noise below the surface conjugate depth is relatively more sensitive to sources within a convergence zone of the receiver location.

\section{2010-2011 NPAL PHILIPPINE SEA EXPERIMENT (PhilSea10)}

The 2010-2011 NPAL Philippine Sea deep-water acoustic propagation experiment combined measurements of acoustic propagation and ambient noise with the use of an ocean acoustic tomography array to help characterize this oceanographically complex and highly dynamic region.

\section{A. Experiment}

A full water-column-spanning DVLA consisting of five 1000-m subarrays was deployed within an array of six broadband acoustic transceivers (T1-T6) from April 2010 until March-April 2011 (Fig. 10). The DVLA recorded the transmissions from the six sources to study acoustic propagation and scattering. Each acoustic transceiver also recorded the transmissions from the other transceivers, forming a sixelement ocean acoustic tomography array with a radius of approximately $330 \mathrm{~km}$. Following deployment of the moorings, acoustic sources suspended from shipboard transmitted to the DVLA during May 2010 and again during July 2010. Table IV gives the nominal mooring and ship station locations. The DVLA was deployed at nearly the same location as the PhilSea09 DVLA. The ranges (WGS84) from the reference positions of the moored sources (T1-T6) to the

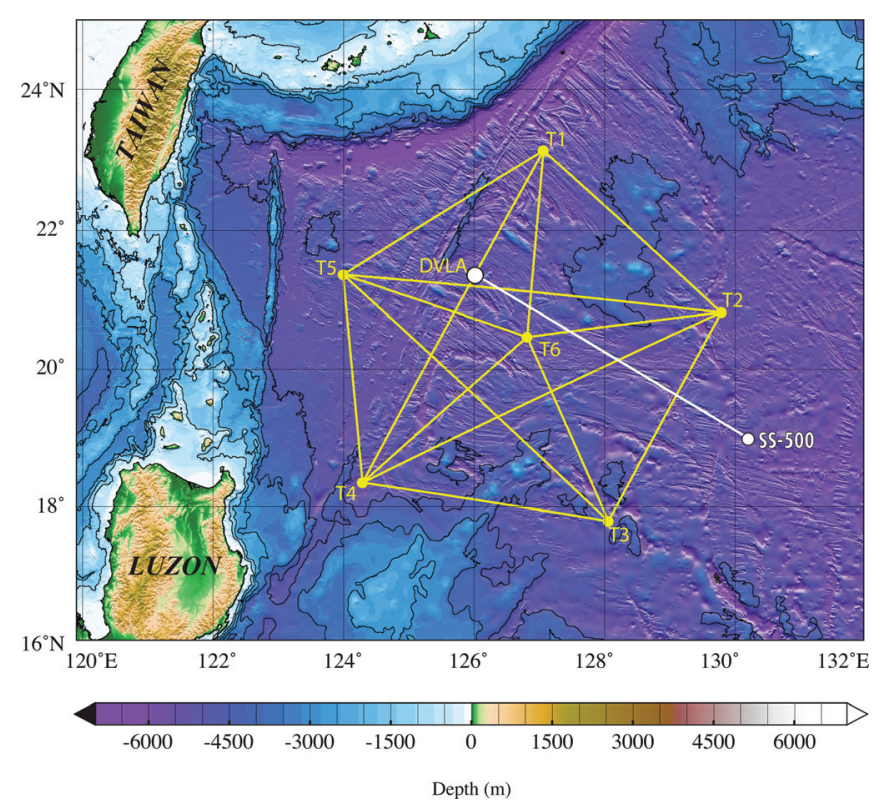

FIG. 10. Geometry of the PhilSea10 experiment. Broadband acoustic transceivers were moored at T1-T6. A DVLA receiver was moored at DVLA. During May 2010, MP-200 Multiport and HX-554 sources suspended from shipboard at ship station SS-500 transmitted to the DVLA. During July 2010, a J15-3 source suspended from shipboard transmitted to the DVLA at fixed locations approximately one-half and one convergence zone from the DVLA and during a number of tows (not shown). Four acoustic Seagliders operated within the array from November 2010 to April 2011. 
TABLE IV. Nominal locations of the moorings and ship stations during PhilSea10. Water depths are corrected depths.

\begin{tabular}{lccc}
\hline \hline & Location & $\begin{array}{c}\text { Source } \\
\text { Depth }(\mathrm{m})\end{array}$ & $\begin{array}{c}\text { Water } \\
\text { Depth (m) }\end{array}$ \\
\hline DVLA & $21^{\circ} 21.7418^{\prime} \mathrm{N}, 126^{\circ} 00.7867^{\prime} \mathrm{E}$ & & 5521 \\
T1 & $23^{\circ} 08.3817^{\prime} \mathrm{N}, 127^{\circ} 04.0753^{\prime} \mathrm{E}$ & 1068.7 & 5939 \\
$\mathrm{~T} 2$ & $20^{\circ} 49.5130^{\prime} \mathrm{N}, 129^{\circ} 46.8332^{\prime} \mathrm{E}$ & 1070.1 & 5940 \\
$\mathrm{~T} 3$ & $17^{\circ} 47.2565^{\prime} \mathrm{N}, 128^{\circ} 03.4890^{\prime} \mathrm{E}$ & 1062.4 & 5755 \\
$\mathrm{~T} 4$ & $18^{\circ} 21.0740^{\prime} \mathrm{N}, 124^{\circ} 17.3629^{\prime} \mathrm{E}$ & 1064.6 & 5786 \\
T5 & $21^{\circ} 21.9914^{\prime} \mathrm{N}, 123^{\circ} 59.2687^{\prime} \mathrm{E}$ & 1061.7 & 5440 \\
T6 & $20^{\circ} 28.0546^{\prime} \mathrm{N}, 126^{\circ} 48.7610^{\prime} \mathrm{E}$ & 1066.0 & 5600 \\
SS-500 & $19^{\circ} 00.00^{\prime} \mathrm{N}, 130^{\circ} 12.00^{\prime} \mathrm{E}$ & 998 & \\
\hline \hline
\end{tabular}

reference position of the DVLA extended from $129.355 \mathrm{~km}$ (T6-DVLA) to $450.131 \mathrm{~km}$ (T3-DVLA) (Table V).

\section{Moored transceivers}

All six of the moored sources were Teledyne Webb Research swept-frequency acoustic sources the performances of which were similar to the source deployed during PhilSea09. Five of the sources transmitted 135-s linear frequency modulated (LFM) signals with bandwidths of $100 \mathrm{~Hz}$ and center frequencies of approximately $250 \mathrm{~Hz}$ (Table VI). One source (T2) transmitted a 135-s, 140-205 Hz LFM signal. The average transmitted power levels varied from 181.9 to $185.8 \mathrm{~dB}$ re $1 \mu \mathrm{Pa}$ at $1 \mathrm{~m}$ rms. The sources transmitted every $3 \mathrm{~h}$ every other day. Sources T1 through T5 transmitted throughout the year. Source T6 failed prematurely, with the last transmission occurring on year day 305 of 2010 (1 November 2010). Transmissions from the six sources were sequenced at 9-min intervals during each transmission hour to avoid interference (Table VI).

The median source depths were 1060-1070m (Table IV). An array of four hydrophones spaced $9.0 \mathrm{~m}$ apart was located above each source to record the transmissions from the other sources. Although the source at T6 failed prematurely, the transceiver continued to record the transmissions from the other sources for the remainder of the experiment. Long-baseline acoustic navigation systems with three acoustic transponders on the seafloor were used to determine the source positions once per hour.

\section{DVLA}

The DVLA consisted of five 1000-m subarrays, with a combined total of 150 hydrophone modules, with D-STAR

TABLE V. Ranges $(\mathrm{km})$ between the reference positions of the moored instruments during PhilSea10 (WGS84).

\begin{tabular}{lccccccc}
\hline \hline & T1 & T2 & T3 & T4 & T5 & T6 & DVLA \\
\hline T1 & 0 & 379.664 & 601.464 & 603.925 & 373.281 & 297.052 & 224.844 \\
T2 & & 0 & 381.867 & 637.818 & 604.828 & 311.811 & 395.938 \\
T3 & & & 0 & 403.813 & 582.464 & 324.301 & 450.131 \\
T4 & & & 0 & 335.292 & 353.710 & 379.080 \\
T5 & & & & 0 & 310.254 & 210.055 \\
T6 & & & & & 0 & 129.355 \\
DVLA & & & & & & 0 \\
\hline \hline
\end{tabular}

TABLE VI. Moored acoustic source characteristics and transmission times during PhilSea10. Average power levels are rms. Transmission times are in minutes after the hour.

\begin{tabular}{lcccc}
\hline \hline Source & S/N & LFM bandwidth $(\mathrm{Hz})$ & $\begin{array}{c}\text { Average power level } \\
(\mathrm{dB} \text { re } 1 \mu \text { Pa at } 1 \mathrm{~m})\end{array}$ & $\begin{array}{c}\text { Transmission } \\
\text { Time (min) }\end{array}$ \\
\hline T1 & 4 & $200-300$ & 184.4 & 0 \\
T2 & 6 & $140-205$ & 183.8 & 9 \\
T3 & 1 & $225-325$ & 181.9 & 18 \\
T4 & 2 & $225-325$ & 182.7 & 27 \\
T5 & 7 & $205-305$ & 184.0 & 36 \\
T6 & 5 & $200-300$ & 185.8 & 45 \\
\hline \hline
\end{tabular}

controllers at the top of each subarray. The number of hydrophone modules varied from subarray to subarray (Table VII). The hydrophone modules spanning the sound-channel axis, which is at $1000-1100 \mathrm{~m}$ depth throughout the year at the DVLA location, were spaced $20 \mathrm{~m}$ apart to resolve the low-order modes for transmissions from the moored sources and the near-axial ship-suspended sources (Fig. 11). The hydrophone modules were more widely spaced over the rest of the water column to characterize the acoustic time fronts and ambient noise field. As in PhilSea09, a long-baseline acoustic navigation system with four acoustic transponders on the seafloor was used to determine the array position and shape once per hour throughout the experiment (Fig. 12).

The DVLA recorded all of the transmissions from the moored sources. As for PhilSea09, the DVLA recorded for $155 \mathrm{~s}$ beginning $10 \mathrm{~s}$ prior to the nominal arrival time of the transmissions from the moored sources to provide approximately 10 -s buffer periods before and after the receptions. In addition, the DVLA recorded continuously at times when the ship-suspended sources were scheduled to be transmitting, except for intervals once per hour to allow the longbaseline navigation system to measure the mooring motion, as described in the following text.

\section{Ship-suspended sources: May 2010}

MP-200 Multiport and HX-554 sources were suspended from the $R / V$ Roger Revelle at different times during May 2010 to transmit to the DVLA (Andrew et al., 2010).

The MP-200 Multiport source was the same as that used during PhilSea09, but it transmitted a more complex signal to better exploit the doubly resonant response of the MP200. A composite drive signal was constructed by summing two 1023-digit, phase-coded, periodic $m$-sequences with

TABLE VII. Nominal hydrophone module depths and spacing in the PhilSea10 DVLA.

\begin{tabular}{lrcc}
\hline \hline Subarray & Depths $(\mathrm{m})$ & Spacing $(\mathrm{m})$ & Number of modules \\
\hline 1 & $180-540$ & 40 & 10 \\
& $580-1180$ & 20 & 31 \\
2 & $1200-2120$ & 20 & 47 \\
& $2160-2200$ & 40 & 2 \\
3 & $2280-3240$ & 60 & 17 \\
4 & $3360-4320$ & 60 & 17 \\
5 & $4383-5381$ & 40 & 26 \\
\hline \hline
\end{tabular}



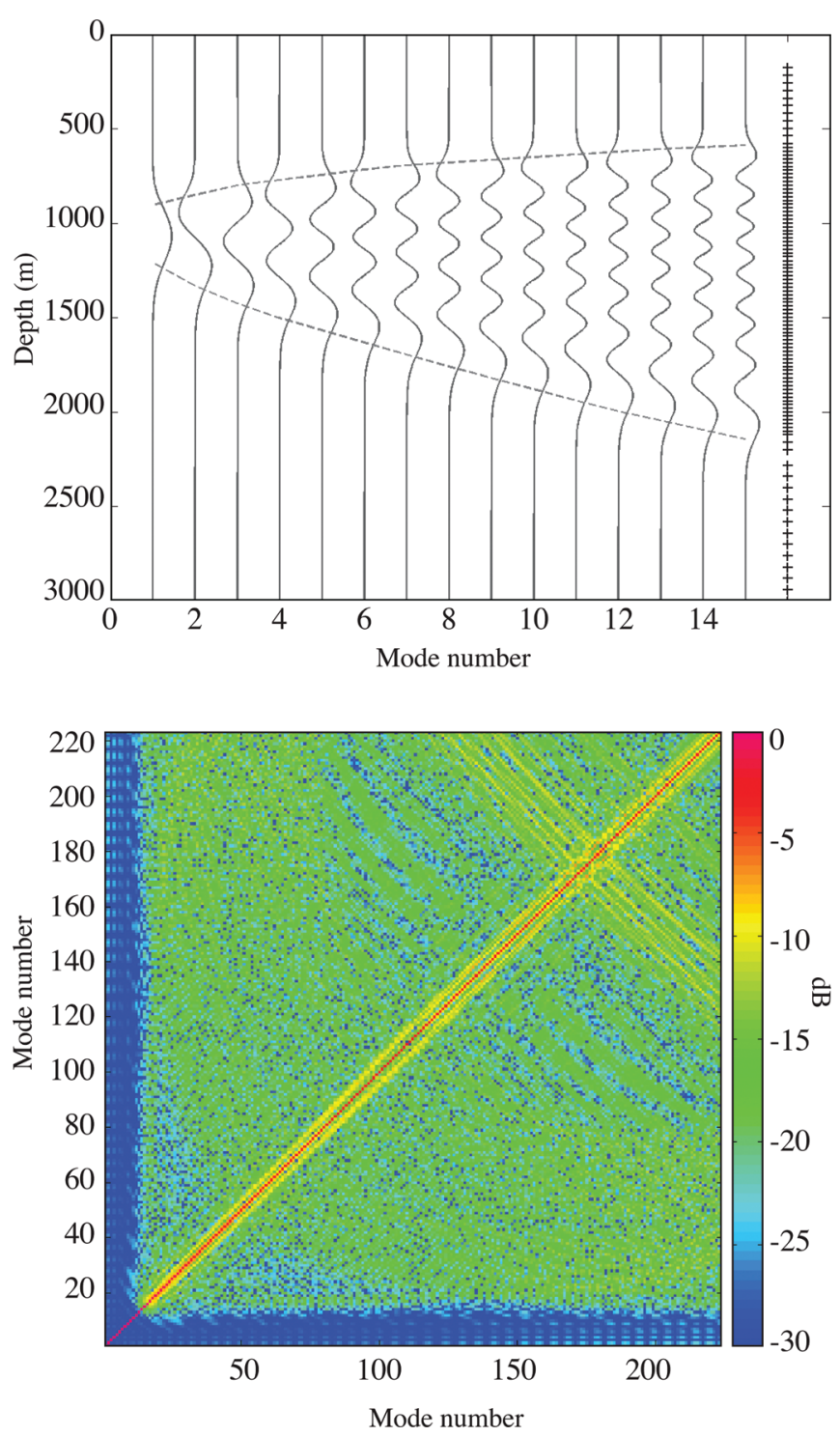

FIG. 11. (Upper) Acoustic normal modes and turning depths for the lowest modes at $75 \mathrm{~Hz}$, corresponding approximately to the carrier frequencies of the ship-suspended HX-554 transmissions. The nominal PhilSea10 DVLA hydrophone locations are shown on the right. (Lower) Sampled modeshape correlation matrix $(\mathrm{dB})$ at $75 \mathrm{~Hz}$ for the PhilSea10 DVLA.

different carrier frequencies $(200$ and $300 \mathrm{~Hz})$ but identical periods $(20.4600 \mathrm{~s})$ (Table III). The periods were kept the same by using four cycles per digit for the $200-\mathrm{Hz}$ signal and six cycles per digit for the $300-\mathrm{Hz}$ signal. The rms source level was approximately $191 \mathrm{~dB}$ re $1 \mu \mathrm{Pa}$ at $1 \mathrm{~m}$. The first transmission event during the cruise consisted of $55 \mathrm{~h}$ of transmissions from the MP-200 Multiport source at a depth of $998 \mathrm{~m}$ at ship station SS-500, located $509.784 \mathrm{~km}$ to the east-southeast of the DVLA (Fig. 10).

The HX-554 source was originally developed for the Acoustic Thermometry of Ocean Climate project by Alliant Techsystems, Inc. (ATOC Instrumentation Group, 1995). It was subsequently modified so that it could be suspended from shipboard. The second transmission event during the cruise consisted of $10 \mathrm{~h}$ of transmissions from the HX-554 source at a depth of $150 \mathrm{~m}$ as it drifted away from the DVLA on an approximately radial course at $1 \mathrm{kn}$. The ranges during the drift increased from about 25 to $43 \mathrm{~km}$. During this event
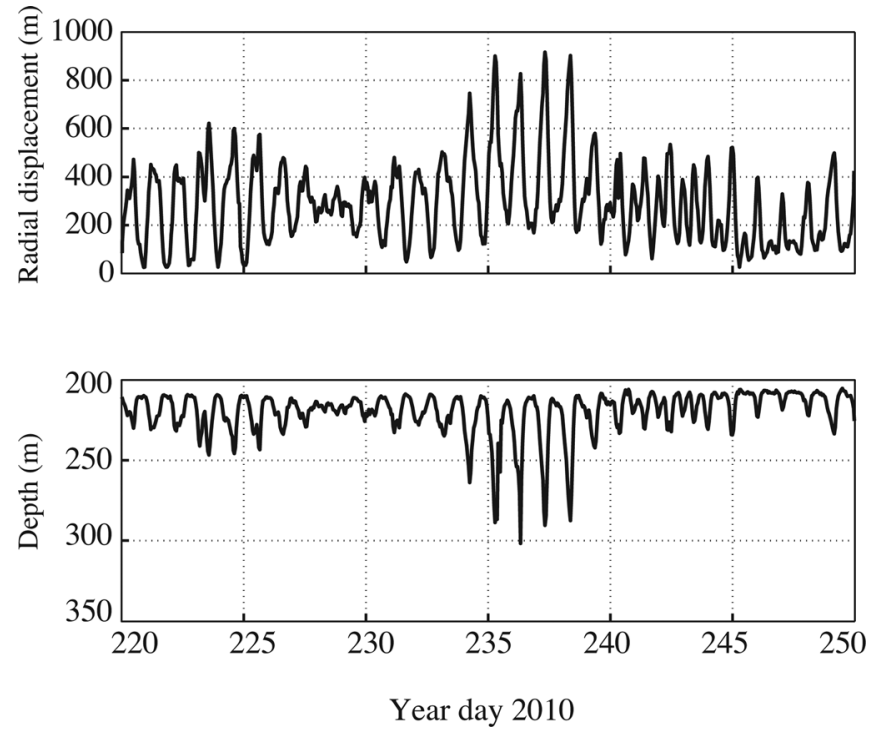

FIG. 12. Radial displacement (upper) and depth (lower) of the D-STAR controller for the top subarray on the PhilSea10 DVLA for year days $220-250$ of 2010 .

the HX-554 source transmitted a 1023-digit, phase-coded, periodic $m$-sequence with a carrier frequency of $61.38 \mathrm{~Hz}$ and two cycles per digit (Table III). The rms source level was approximately $185 \mathrm{~dB}$ re $1 \mu \mathrm{Pa}$ at $1 \mathrm{~m}$. The final transmission event during the cruise consisted of $54 \mathrm{~h}$ of transmissions from the HX-554 source at a depth of $998 \mathrm{~m}$ at ship station SS-500. During this final event, the HX-554 source transmitted a 2047-digit, phase-coded, periodic $m$-sequence with a carrier frequency of $81.88 \mathrm{~Hz}$ and two cycles per digit (Table III). The rms source level was approximately $186 \mathrm{~dB}$ re $1 \mu \mathrm{Pa}$ at $1 \mathrm{~m}$. The objective of the near-continuous transmissions from ship station SS-500 was to study the fluctuation statistics of the signals as received on the DVLA. The goal of the drift experiment was to study the reliable acoustic path as it crosses the bottom-limited region.

At SS-500 the positions of the MP-200 and the HX-554 sources were tracked with a long-baseline acoustic navigation system using acoustic transponders on the seafloor.

\section{Ship-suspended source: July 2010}

A J15-3 source was suspended from the $R / V$ Roger Revelle during the Mobile Operations cruise in July 2010 to transmit to the DVLA. The objectives were to study (1) bottom bounce propagation paths, including the dependence on bathymetry at ranges of one-half and one convergence zone, seamount scattering, and the impact of seafloor roughness; (2) the effects of ocean mesoscale variability on deep-water propagation; (3) long-range matched field processing; and (4) coherent bandwidth as a function of range and frequency. In addition, low frequency analysis and recording sonobuoys (AN/SSQ-57B) were used to record the transmissions from moored sources T1-T6.

The J15-3 source transmitted a combination of CW and LFM signals at fixed locations approximately one-half and one convergence zone from the DVLA and during a number of tows. One of the tows included a "Star-of-David" pattern 
approximately one-half convergence zone $(\sim 33 \mathrm{~km})$ from the DVLA.

\section{Acoustic seagliders}

Four acoustic Seagliders were deployed during November 2010 in the vicinity of the PhilSea10 moored array (Howe et al., 2011; Van Uffelen et al., 2013). The gliders measured temperature and salinity in the upper $1000 \mathrm{~m}$ of the ocean between the moorings and recorded the transmissions from the moored acoustic sources. Two of the Seagliders entered recovery mode prematurely due to technical problems but were nonetheless successfully recovered.

A major objective was to determine whether, given the joint nature of the combined navigation/tomography problem, it is possible to use Seagliders equipped with an acoustic recorder system (ARS) as mobile nodes in a tomographic array, thereby enhancing the resolution of the tomographic system. The ARS collected data at a sampling rate of $4000 \mathrm{~Hz}$ for approximately $3200 \mathrm{~s}$ beginning at the T1 transmit time (Table VI) to receive the transmissions from all six moored sources. As noted in the preceding text, the source at T6 stopped transmitting before the Seagliders were deployed, however.

\section{Environmental measurements}

The upper part of the DVLA was populated with Seabird MicroCATs (SBE 37-SMP) to measure temperature and salinity, with instruments placed at depths derived from WKB baroclinic scaling between approximately 130 and $550 \mathrm{~m}$. The sample interval was 240 or $360 \mathrm{~s}$, depending on the instrument. In addition, all of the hydrophone modules on the DVLA measured temperature, providing precision temperature data over nearly the full water column. The sample interval was normally $20 \mathrm{~min}$, but decreased to $5 \mathrm{~min}$ during times that the DVLA was recording continuously.

Moorings T1-T5 were populated with Sea-Bird MicroCATs (SBE 37-SM/SMP) and temperature recorders (SBE 39) with instrument depths selected to best resolve the first five internal tide modes, giving depths approximately between 180 and $1920 \mathrm{~m}$. (Mooring T6 did not have any environmental instrumentation.) The MicroCATs were at depths of about $180 \mathrm{~m}$ (on the subsurface floats) and $650 \mathrm{~m}$. The sample interval for the MicroCATs was 240 or $480 \mathrm{~s}$, depending on the instrument. The temperature recorders sampled at 240-s intervals.

Near-surface currents were measured using a downwardlooking RDI WHS $150-\mathrm{kHz}$ ADCP at about 155-m depth on the DVLA and upward-looking RDI WHS 300-kHz ADCPs at about 360-m depth on moorings T1-T5. The ADCP on the DVLA sampled at 20-min intervals, while the ADCPs on moorings T1-T5 sampled at 15-min intervals.

CTD casts were made near the moorings. A highresolution CTD section was made along the acoustic path between SS-500 and the DVLA. The survey included 51 CTD casts spaced every $10 \mathrm{~km}$. Most of the casts were to $1500 \mathrm{~m}$, but every fifth cast was to full ocean depth. Finally, Seagliders made CTD measurements down to 1000$\mathrm{m}$ depth throughout the mooring array, as noted in the preceding text.
Finally, an 800-m "towed conductivity-temperaturedepth chain" using inductively coupled sensors was towed along the geodesic between SS-500 and the DVLA. Unfortunately, the instrument performed poorly, producing only a small subset of useable data.

\section{B. Selected results}

The acoustic time fronts recorded on the near-water-column-spanning DVLA provide a rich data set on the acoustic variability. The time fronts for transmissions from T3 at about 450-km range, for example, show substantially less scattering of the near-axial finale than is evident at $500-\mathrm{km}$ range in the central North Pacific (Fig. 13) (Van Uffelen et al., 2009, 2010). The internal-wave energy levels found in the Philippine Sea are somewhat higher than those in the central North Pacific (Colosi et al., 2013), suggesting that the difference in behavior of the near-axial finale is associated with the shape of the mean sound-speed profile.

Although the DVLA did not record any noise-only receptions during PhilSea10, it nonetheless provided information on ambient noise levels throughout the water column and over the 1-year deployment for frequencies outside the band occupied by the signals transmitted by the moored sources. The minimum omnidirectional ambient noise levels observed at the DVLA decrease below the surface conjugate depth at frequencies from 20 to $400 \mathrm{~Hz}$ (Fig. 14). The minimum noise level at the deepest hydrophone, approximately $134 \mathrm{~m}$ above the sea floor, was about $61 \mathrm{~dB}$ re $1 \mu \mathrm{Pa}^{2} / \mathrm{Hz}$ at $50 \mathrm{~Hz}$, which is somewhat less than the level of about $67 \mathrm{~dB}$ re $1 \mu \mathrm{Pa}^{2} / \mathrm{Hz}$ previously observed $20-30 \mathrm{~m}$ above the seafloor in shorter duration measurements. The decrease of about $15 \mathrm{~dB}$ from the level found near the sound-channel axis is still not as great as the decrease of 20-25 $\mathrm{dB}$ found in the Northeast Pacific, however (Shooter et al., 1990; Gaul et al., 2007). The minimum noise levels presumably correspond to times when there are no nearby ships, wind speeds

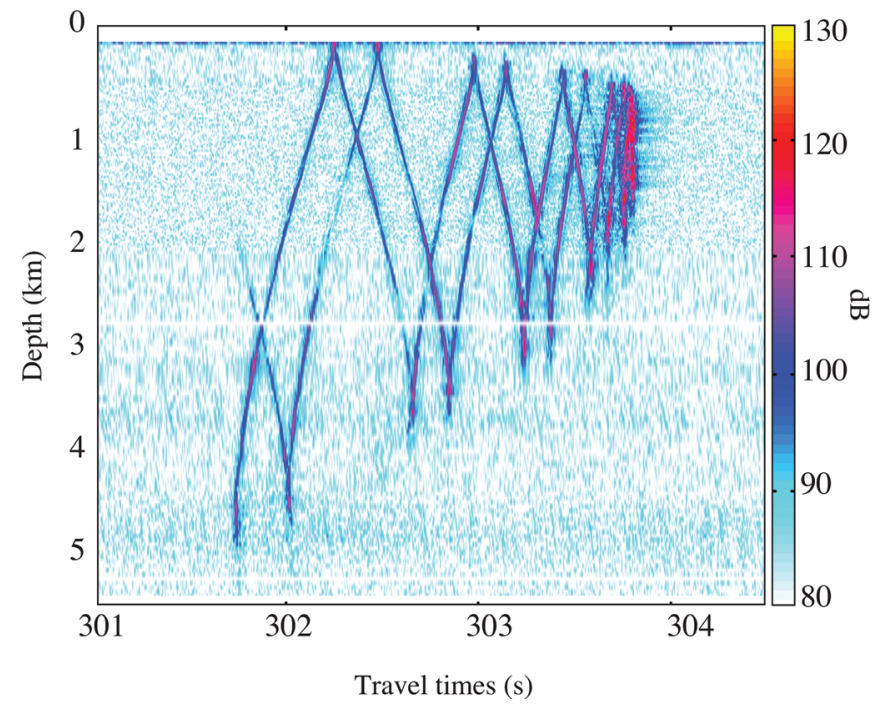

FIG. 13. Acoustic time front on the DVLA for a transmission from mooring $\mathrm{T} 3$ at about $450-\mathrm{km}$ range during PhilSea 10 . The recording was made on 01 May 2010 at 00:18:00 UTC. 


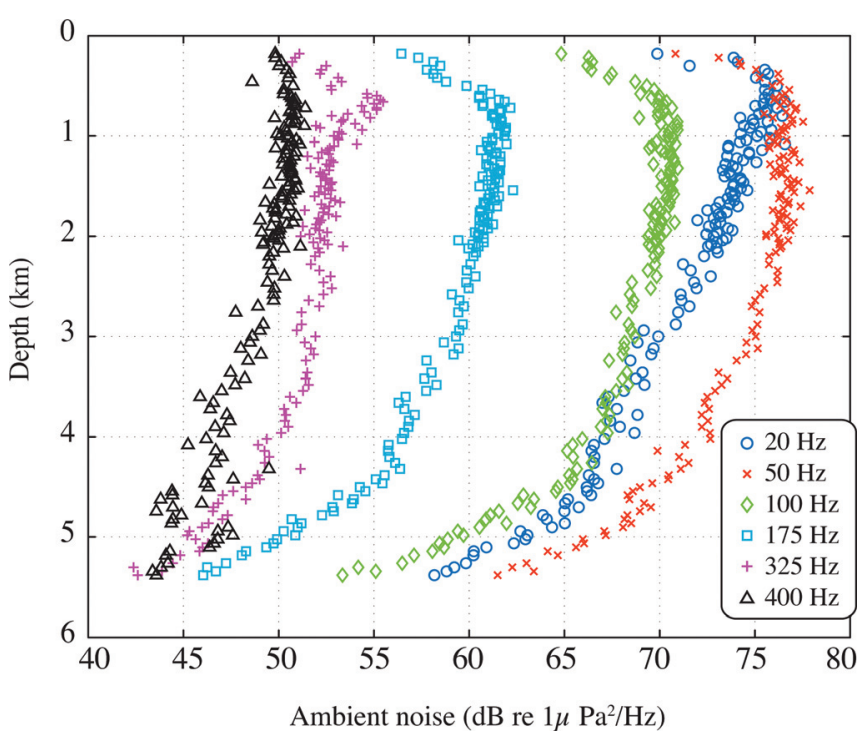

FIG. 14. Minimum omnidirectional ambient noise levels at six frequencies from 20 to $400 \mathrm{~Hz}$ observed on the DVLA during PhilSea10 as a function of depth. These spectra are from the receptions of the T1 transmissions at 0000 UTC on every other day throughout the year (164 receptions).

are low, and surface conditions are calm, so that there is little locally generated noise.

\section{OCEAN BOTTOM SEISMOMETER AUGMENTATION OF THE 2010-2011 NPAL PHILIPPINE SEA EXPERIMENT (OBSAPS)}

A near-seafloor Ocean Bottom Seismometer Augmentation of the 2010-2011 NPAL Philippine Sea Experimentdistributed vertical line array (O-DVLA) and array of ocean bottom seismometers (OBS) were deployed in the Philippine Sea during April-May 2011, immediately following recovery of the PhilSea10 moorings, to study the relationship between the acoustic field in the water column and the seismic field in the seafloor for both ambient noise and signals transmitted by a J15-3 source (Stephen et al., 2011). The experiment was motivated in part by unexpected arrivals observed on OBSs at 5000-m depth in the Northeast Pacific from broadband signals transmitted by a ship-suspended $75-\mathrm{Hz}$ source during the 2004 Long-range Ocean Acoustic Propagation Experiment (LOAPEX) (Mercer et al., 2009; Stephen et al., 2009, 2012). These arrivals were named Deep SeaFloor (DSF) arrivals. Many, although not all, of the DSF arrivals observed during LOAPEX are now known to correspond to

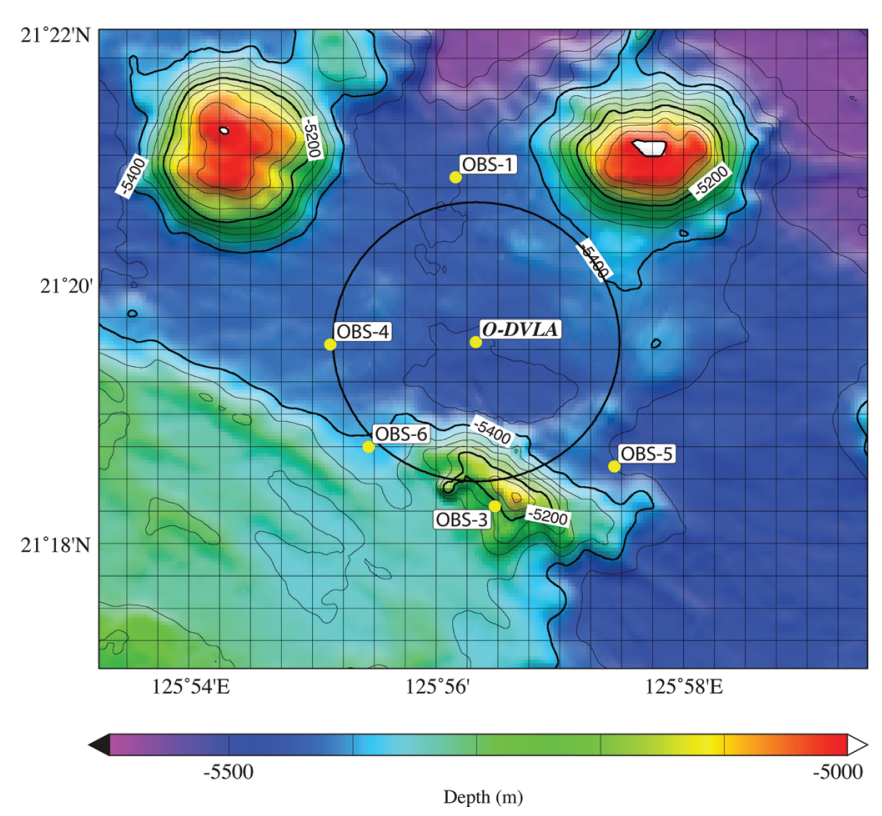

FIG. 15. Geometry of the OBSAPS experiment. A DVLA extending up $1000 \mathrm{~m}$ from the seafloor was moored at O-DVLA. Short-period OBS were deployed at OBS-1, OBS-3, and OBS-4. Long-period, broadband OBS were deployed at OBS-5 and OBS-6. (OBS-2 flooded and yielded no data.) The circle centered on O-DVLA has a radius of $2 \mathrm{~km}$. A J15-3 source suspended from shipboard transmitted to the O-DVLA and OBS at fixed locations and during tows along radial lines and in a "Star-of-David" pattern (not shown).

energy that scattered into high angles at a small, out-plane seamount about $18 \mathrm{~km}$ from the OBS, subsequently reflected from the sea surface, and then arrived at the OBS (Stephen et al., 2013).

\section{A. Experiment}

The 1000 -m long O-DVLA extending up from the seafloor was deployed within an array of six OBS (Fig. 15). (One OBS flooded and yielded no data.) The O-DVLA and OBS remained in place for approximately 1 month while a J15-3 source suspended from shipboard transmitted to them. Table VIII gives the O-DVLA and OBS positions.

\section{Near-seafloor DVLA}

The O-DVLA consisted of a single 1000-m subarray with 15 hydrophone modules and a D-STAR controller at the top. The deepest hydrophone module was located $12 \mathrm{~m}$ above the seafloor. The bottom eight hydrophone modules

TABLE VIII. O-DVLA and OBS locations during OBSAPS (OBS-2 flooded and yielded no data). Hydrophone modules identical to those in the O-DVLA were attached to the three short-period OBS. The O-DVLA depth is from a multibeam measurement made at the surveyed mooring location. The OBS depths are estimated at the surveyed OBS locations from multibeam data gridded at 125 -m spacing. Water depths are corrected depths.

\begin{tabular}{lcc}
\hline \hline & Instrument type & \multicolumn{1}{c}{ Location } \\
\hline O-DVLA & Water Depth (m) \\
OBS-1 & Short period & $21^{\circ} 19.5594^{\prime} \mathrm{N}, 125^{\circ} 56.3247^{\prime} \mathrm{E}$ \\
OBS-3 & Short period & $21^{\circ} 20.8316^{\prime} \mathrm{N}, 125^{\circ} 56.1601^{\prime} \mathrm{E}$ \\
OBS-4 & Short period & $21^{\circ} 18.2867^{\prime} \mathrm{N}, 125^{\circ} 56.4779^{\prime} \mathrm{E}$ \\
OBS-5 & Long period (broadband) & $21^{\circ} 19.5387^{\prime} \mathrm{N}, 125^{\circ} 55.1455^{\prime} \mathrm{E}$ \\
OBS-6 & Long period (broadband) & $21^{\circ} 18.5955^{\prime} \mathrm{N}, 125^{\circ} 57.4424^{\prime} \mathrm{E}$ \\
\hline \hline
\end{tabular}


TABLE IX. Nominal hydrophone module heights above the seafloor and spacing in the O-DVLA.

\begin{tabular}{lcc}
\hline \hline Height $(\mathrm{m})$ & Spacing $(\mathrm{m})$ & Number of modules \\
\hline $12-82$ & 10 & 8 \\
132 & 50 & 1 \\
$252-852$ & 120 & 6 \\
\hline \hline
\end{tabular}

were spaced $10 \mathrm{~m}$ apart (approximately $\lambda / 2$ at $75 \mathrm{~Hz}$ ) to provide information immediately above the seafloor on the angular dependence of both ambient noise and the signals transmitted by the J15-3 source (Table IX). The upper hydrophone modules were spaced $120 \mathrm{~m}$ apart, with the shallowest $852 \mathrm{~m}$ above the seafloor, extending up to approximately the surface conjugate depth.

The O-DVLA recorded continuously during the time that J15-3 transmissions were scheduled, other than short gaps once per hour to allow for positioning of the mooring using a long-baseline acoustic navigation system. The sample rate was $1953.125 \mathrm{~Hz}$.

\section{Ocean bottom seismometers}

Three of the OBS were short-period instruments that sampled at $1000 \mathrm{~Hz}$ (OBS-1, OBS-3, and OBS-4) (Table VIII). Each unit had a Mark Products L28 gimbaled threecomponent geophone and a High Tech, Inc., HTI-90-U hydrophone. Two of the OBS were long-period, broadband instruments that sampled at $200 \mathrm{~Hz}$ (OBS-5, OBS-6). Each long-period instrument had a Nanometrics Trillium 240 (T240) seismometer and a differential pressure gauge (DPG). Hydrophone modules identical to those used in the DVLA, but set to operate autonomously, were attached to the three short-period instruments. The sample rate of the hydrophone modules on the OBS was the same as the sample rate of the hydrophone modules in the O-DVLA, i.e., $1953.125 \mathrm{~Hz}$.

\section{Ship-based instrumentation}

A J15-3 source was suspended from the $R / V$ Roger Revelle to transmit to the O-DVLA and OBS. Except for a few engineering tests, all of the transmissions were phasecoded, periodic $m$-sequences with carrier frequencies of 77.5, $102.3,155.0,204.6$, or $310.0 \mathrm{~Hz}$ (Table X). The source transmitted both at fixed locations and during tows along radial lines and in a "Star-of-David" pattern about one-half convergence zone $(\sim 35 \mathrm{~km})$ from the O-DVLA. The nominal source

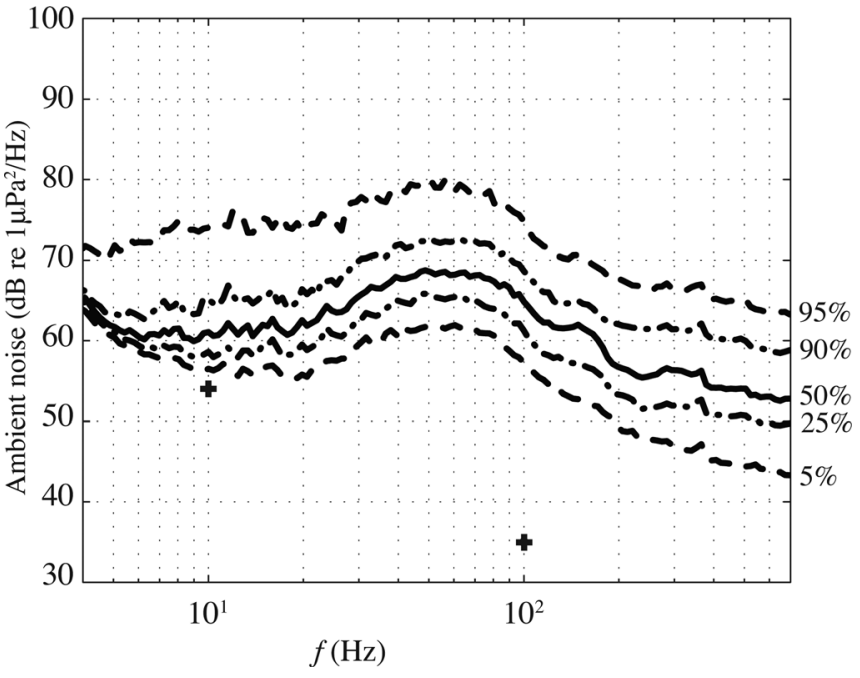

FIG. 16. Ambient noise spectra at OBS-1 (North) during OBSAPS. The spectra show the 5th, 25th, 50th, 75th, and 90th percentiles of the power spectral densities computed from data recorded on the hydrophone module attached to OBS-1. The equivalent self-noise levels for the HTI-90-U hydrophone at 10 and $100 \mathrm{~Hz}$ are shown as crosses (Table XI).

depth for all events was $60 \mathrm{~m}$, although the depth varied somewhat depending on tow speed.

\section{Environmental measurements}

The hydrophone modules on the O-DVLA and OBSs measured temperature at 5-min intervals when recording continuously, increasing to 15-min intervals on the O-DVLA when it was in standby before and after the continuous recording period. Near-seafloor currents at the O-DVLA were measured using a Nortek 6000-m Aquadopp current meter located $10.5 \mathrm{~m}$ above the seafloor. It generated a 5 -s average at 10-s intervals. Finally, CTD, XBT, and expendable sound velocity casts were made in the experimental area.

\section{B. Selected results}

The OBS provided measurements of ambient noise levels on the seafloor. The 5th percentile of the power spectral densities computed from data recorded on the hydrophone module attached to OBS-1 (North) during the OBSAPS experiment (Fig. 16) had the same omnidirectional noise level at $50 \mathrm{~Hz}\left(61 \mathrm{~dB}\right.$ re $\left.1 \mu \mathrm{Pa}^{2} / \mathrm{Hz}\right)$ as the minimum level observed $134 \mathrm{~m}$ above the seafloor on the deepest hydrophone in the DVLA during PhilSea10 (Fig. 14). The 5th percentile of the power spectral densities at $10 \mathrm{~Hz}$ was about

TABLE X. Parameters of the periodic phase-coded $m$-sequence signals transmitted by the J15-3 source during the OBSAPS experiment. Signals with both two and four cycles per digit were transmitted at 155.0 and $310.0 \mathrm{~Hz}$.

\begin{tabular}{lccccc}
\hline \hline Carrier frequency (Hz) & 77.5 & 102.3 & 155.0 & 204.6 & 2 \\
Cycles/digit & 2 & 2 & $2 / 4$ & 210.0 & $2 / 4$ \\
Digit length (ms) & 25.8065 & 19.5503 & $12.9032 / 25.8065$ & 9.7752 & 1023 \\
Sequence length (digits) & 1023 & 1023 & 1023 & $10.4516 / 12.9032$ \\
Sequence period (s) & 26.4000 & 20.0000 & $13.2000 / 26.4000$ & 20000 & $6.6000 / 13.2000$ \\
Sequence law & $2033_{8}$ & $2033_{8}$ & $2033_{8}$ & $2033_{8}$ \\
Phase modulation angle & $88.209^{\circ}$ & $88.209^{\circ}$ & $88.209^{\circ}$ & $88.209^{\circ}$ & $88.209^{\circ}$ \\
\hline \hline
\end{tabular}


$57 \mathrm{~dB}$ re $1 \mu \mathrm{Pa}^{2} / \mathrm{Hz}$. This level is only $3 \mathrm{~dB}$ above the equivalent self-noise level of the HTI-90-U hydrophone (Table XI), suggesting that the ambient noise measurements at low frequencies may have been system-noise limited a few percent of the time.

\section{CONCLUDING REMARKS}

This paper provides only a brief introduction to the three experiments conducted by the NPAL Group in the Philippine Sea during 2009-2011 to study deep-water acoustic propagation and ambient noise. All three experiments were enabled by a newly developed DVLA receiver that provided the flexibility to easily provide differing VLA geometries in the three experiments. The DVLA spanned nearly the full water column in water $5521 \mathrm{~m}$ deep during PhilSea10, enabling the separation of acoustic modes using spatial filtering and full characterization of the acoustic time fronts.

The detailed results from these experiments, as well as related analyses, will appear in a series of papers, including at present Colosi et al. (2013), Freeman et al. (2013), Heaney et al. (2013), Powell et al. (2013), Van Uffelen et al. (2013), and White et al. (2013). The selected results presented here have emphasized the ambient noise measurements only because those analyses are among the more straightforward. A series of additional papers exploring these data sets is expected.

\section{ACKNOWLEDGMENTS}

The success of the NPAL series of Philippine Sea experiments is the result of the efforts of many people, including the Captains and crews of the $R / V$ Kilo Moana, $R / V$ Melville, and $R / V$ Roger Revelle and individuals at the Applied Physics Laboratory of the University of Washington (B. Bell, E. Boget, R. Bolstad, C. Fletcher, A. Ganse, L. Gullings, F. Karig, T. McGinnis, S. McPeak, J. Sellschopp, T. Wen, and A. White), the Naval Postgraduate School (C. Miller, M. Stone, and K. Wycoff), OASIS, Inc. (R. Campbell and J. Murray), Scripps Institution of Oceanography (E. Aaron, B. Moskovitz, S. Carey, L. Green, D. Horwitt, S. Lynch, S. McPeak, M. Norenberg, and K. Scott), University of Hawaii (G. Carter, L. Fujieki, J. Mowatt, E. Nosal, and S. Poulos), and Woods Hole Oceanographic Institution (S. T. Bolmer, J. Dunn, K. Newhall, and J. Ryder). The Ocean Bottom Seismometers used in the OBSAPS experiment were provided by the Scripps Institution of Oceanography as part of the U.S. National Ocean Bottom Seismograph Instrument Pool (OBSIP). T. Bolmer (WHOI) assisted with the figures. This paper is based upon work supported by the Office of Naval Research Ocean Acoustics and Undersea Signal Processing programs.

\section{APPENDIX: DVLA}

A DVLA receiver that is capable of spanning the full water column in water up to $6000 \mathrm{~m}$ deep was developed for the NPAL Philippine Sea experiments (Worcester et al., 2009). Water-column-spanning arrays enable separation of acoustic modes using spatial filtering and full characterization of the acoustic time fronts formed in broadband, deep-water propagation. The DVLA is made up of distributed, selfrecording hydrophone modules (Fig. 17) with timing and scheduling provided by a small number of central controllers, called D-STARs. The enabling technologies for this approach are (1) the availability of flash memory modules that can store gigabytes of data and be located in a small pressure case at each hydrophone, making it unnecessary to transfer data from the hydrophones to the central controllers for storage, and (2) inductively coupled modems that allow lowbandwidth communication for command, control, and time synchronization between the central controllers and the hydrophone modules over standard oceanographic mooring wire. The DVLA is fully autonomous, recording during time periods specified a priori. The maximum duty cycle for a 1yr deployment is approximately $8 \%$, depending on the sample rate.

The DVLA is modular, consisting of subarrays with a nominal length of $1000 \mathrm{~m}$, each of which has one D-STAR controller and up to 99 hydrophone modules. The D-STAR is placed in-line at the top of each subarray. Hydrophone

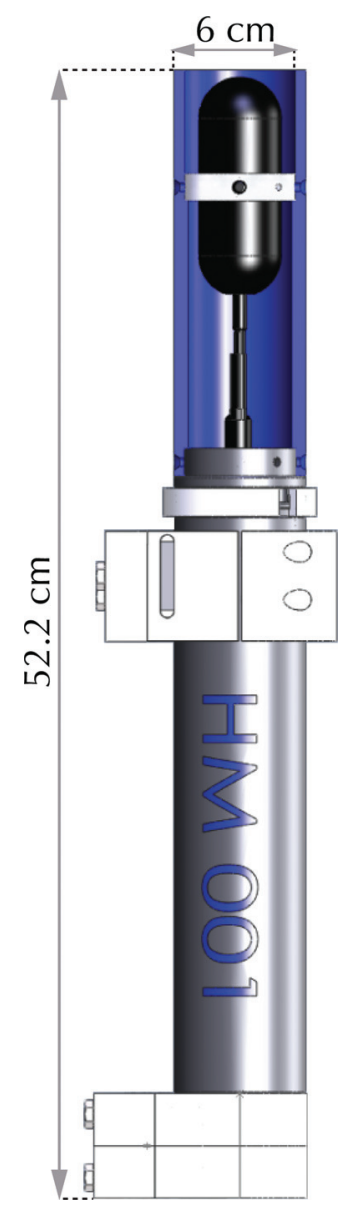

FIG. 17. Hydrophone module used in the DVLA receivers with the dimensions in centimeters. The HTI-90-U hydrophone is encased in a polypropylene sleeve for protection that has been cut away in this drawing to show the hydrophone. The hydrophone module is attached to the mooring wire using the two white clamps with the hydrophone pointing up to ensure that there is no trapped air. The clamp opposite the hydrophone incorporates the split ferrite used by the inductive modem to couple signals to and from the mooring wire. The pressure case is titanium. 
modules are clamped to the mooring wire at the time of deployment, making the DVLA readily configurable for different experiments. The D-STARs and hydrophone modules are rated for operation to a depth of $6000 \mathrm{~m}$. The DVLA uses a long-baseline acoustic navigation system, with acoustic transponders positioned on the seafloor around the mooring, to measure the array position and shape with an absolute accuracy of $\sim 1 \mathrm{~m} \mathrm{rms}$ as the mooring moves in response to ocean currents. The hydrophone modules make precision temperature measurements $\left( \pm 0.005^{\circ} \mathrm{C}\right)$ throughout the time that the DVLA is deployed to provide the sound-speed profiles needed for beamforming.

\section{Inductive modem}

The communication link connecting the hydrophone modules to the D-STAR controller employs inductive modem technology developed by Sea-Bird Electronics, Inc., that uses jacketed oceanographic wire rope, avoiding the need for a custom electromechanical array cable (Sea-Bird Electronics, Inc., 2012). Inductively coupled modems use toroidal transformers to couple data to and from instruments clamped on the mooring cable. At each hydrophone module, the mooring cable passes through a ferrite toroid, forming a single-turn primary winding for data transferred from the DSTAR controller to the hydrophone module. The hydrophone module has a 20-turn secondary winding to receive the data. The toroids are split in halves, so that they can be clamped around the cable without the need to thread the mooring cable through the toroid. The inductive modems use differential phase shift key modulation on a $4800-\mathrm{Hz}$ carrier, providing 1200-baud, half-duplex communications. Sea-Bird modified their Inductive Modem Module (IMM) firmware to provide precision time transfer between the DSTAR and the hydrophone modules using the IMM Flag line. Laboratory tests indicate that the modified firmware provides time transfer with a standard deviation of $31 \mu \mathrm{s}$ between hydrophone modules.

\section{D-STAR controller}

The D-STAR provides a precision time base capable of keeping time autonomously with an accuracy of $\sim 1 \mathrm{~ms}$ per year. A low-power $(80 \mathrm{~mW})$ microcomputer compensated crystal oscillator (Q-Tech MCXO QT-2002) serves as the primary system oscillator. A much higher power $(10 \mathrm{~W}$ at $25^{\circ} \mathrm{C}$ operating) rubidium oscillator (Symmetricom X72) is turned on periodically (typically once per day) to serve as a reference to measure the frequency of the QT-2002. The difference frequency is logged and used to correct the D-STAR clock after recovery.

The D-STAR controllers transmitted long-baseline interrogation signals to acoustic transponders on the seafloor once per hour continuously throughout the NPAL Philippine Sea experiments and recorded the replies using a 15-s recording window. There are no electrical connections between the DSTAR controllers in the DVLA. Their clocks are therefore synchronized acoustically using the long-baseline interrogation signals. Each D-STAR records the interrogation signals of the other D-STARs once per hour; this is equivalent to
TABLE XI. Equivalent self-noise vs frequency for the HTI-90-U hydrophone (High Tech, Inc.).

\begin{tabular}{lc}
\hline \hline Frequency $(\mathrm{Hz})$ & Equivalent self-noise $\left(\mathrm{dB}\right.$ re $\left.1 \mu \mathrm{Pa}^{2} / \mathrm{Hz}\right)$ \\
\hline 10 & 54 \\
100 & 35 \\
1000 & 26 \\
\hline \hline
\end{tabular}

having the D-STARs transpond off one another (although with some delay between the interrogate and reply signals) and allows the D-STAR clocks to be compared.

\section{Hydrophone modules}

The hydrophone modules are designed (1) to record low-frequency acoustic signals, sampling at 976.5625, 1953.1250 , or $3906.2500 \mathrm{~Hz}$, (2) to record the highfrequency, long-baseline acoustic navigation signals, sampling at $39062.5 \mathrm{~Hz}$, and (3) to make precision temperature measurements. Separate channels of a quad, 24-bit, deltasigma analog-to-digital converter are used for each of the three measurements. Each hydrophone module saves the data to a 16 GB secure digital (SD) card.

A High Tech, Inc., HTI-90-U hydrophone, which has an integral preamplifier and is rated for operation from $2 \mathrm{~Hz}$ to $20 \mathrm{kHz}$, is used for both the low-frequency acoustic and navigation channels. Its equivalent self-noise is below Sea State 0 (Table XI). The self-noise levels of the signal conditioning circuitry and analog-to-digital converter in the low-frequency acoustic channel are below the equivalent self-noise of the hydrophone. High-pass filters are included in both the hydrophone preamplifier $\left(f_{\text {High-pass }}=10 \mathrm{~Hz}\right)$ and hydrophone module signal conditioning circuitry $\left(f_{\text {High-pass }}=7.7 \mathrm{~Hz}\right)$ to mitigate the effects of low-frequency mooring strum due to vortex-induced vibrations. Nonetheless, the low-frequency acoustic data in the upper 1000-2000 m of the water column are at times significantly contaminated by strumming.

Andrew, R. K. (2009). "The APL/UW Multiport Acoustic Projector System," Technical Report APL-UW TR 0902 (Applied Physics Laboratory, University of Washington, Seattle, WA).

Andrew, R. K., Mercer, J. A., Bell, B. M., Ganse, A. A., Buck, L., Wen, T., and McGinnis, T. M. (2010). "PhilSea10 APL-UW Cruise Report: 5-29 May 2010," Technical Report APL-UW TR 1001 (Applied Physics Laboratory, University of Washington, Seattle, WA), $118 \mathrm{pp}$.

Antonov, J. I., Locarnini, R. A., Boyer, T. P., Mishonov, A. V., and Garcia, H. E. (2006). World Ocean Atlas 2005. Salinity, edited by S. Levitus (U.S. Government Printing Office, Washington, DC), NOAA Atlas NESDIS62, Vol. 2, 182 pp.

ATOC Instrumentation Group (1995). "Instrumentation for the Acoustic Thermometry of Ocean Climate (ATOC) prototype Pacific Ocean network," in OCEANS'95 MTS/IEEE Conference Proceedings (IEEE, New York), pp. 1483-1500.

Becker, K. M., and Preston, J. R. (2003). "The ONR Five Octave Research Array (FORA) at Penn State," in OCEANS 2003 IEEE Conference Proceedings (IEEE, New York), pp. 2607-2610.

Chu, P. C., and Hsieh, C.-P. (2007). "Change of multifractal thermal characteristics in the western Philippine Sea upper layer during internal wavesoliton propagation," J. Oceangr. 63, 927-939.

Colosi, J. A., Van Uffelen, L. J., Cornuelle, B. D., Dzieciuch, M. A., Worcester, P. F., Dushaw, B. D., and Ramp, S. R. (2013). "Observations of sound-speed fluctuations in the western Philippine Sea in the spring of 2009," J. Acoust. Soc. Am. 134, 3185-3200. 
Emery, L., Bradley, M., and Hall, T. (2001). "Database description (DBD) for the Historical Temporal Shipping Database Variable Resolution (HITS), Version 4.0," PSI Technical Report TRS-301 (Planning Systems Incorporated, Slidell, LA), $35 \mathrm{pp}$.

Evans, R. B., and Carey, W. M. (2009). "Basin scale computation of vertical and horizontal directivity of underwater ambient noise, due to shipping and wind," in Proceedings of the Ninth International Conference on Theoretical and Computational Acoustics, edited by S. Marburg (Universität der Bundeswher, Neubiberg, Germany), pp. 373-384.

Freeman, S. E., D’Spain, G. L., Lynch, S. D., Stephen, R. A., Heaney, K. D., Murray, J. J., Baggeroer, A. B., Worcester, P. F., Dzieciuch, M. A., and Mercer, J. A. (2013). "Estimating the horizontal and vertical direction-of-arrival of water-borne seismic signals in the northern Philippine Sea," J. Acoust. Soc. Am. 134, 3282-3298.

Gaul, R. D., Knobles, D. P., Shooter, J. A., and Wittenborn, A. F. (2007). "Ambient noise analysis of deep-ocean measurements in the Northeast Pacific," IEEE J. Ocean. Eng. 32, 497-512.

Goodman, D., Bibee, L. D., and Dorman, L. M. (1989). "Crustal seismic structure beneath the West Philippine Sea, $17^{\circ}-18^{\circ}$ North," Mar. Geophys. Res. 11, 155-168.

Groves, I. D., Jr. (1974). "Twenty years of underwater electroacoustic standards," NRL Report FR-7735 (Naval Research Laboratory, Washington, DC), $132 \mathrm{pp}$.

Heaney, K. D., Campbell, R. L., Murray, J. J., Baggeroer, A. B., Scheer, E. K., Stephen, R. A., D'Spain, G. L., and Mercer, J. A. (2013). "Deep water towed array measurements at close range," J. Acoust. Soc. Am. 134, 3230-3241.

Houtz, R., and Ewing, J. (1976). "Upper crustal structure as a function of plate age," J. Geophys. Res. 81, 2490-2498, doi:10.1029/JB081i014p02490.

Howe, B. M., Van Uffelen, L. J., Nosal, E.-M., and Carter, G. S. (2011). "Acoustic seagliders in PhilSea10: Preliminary results," in OCEANS 2011 IEEE Conference Proceedings (IEEE, New York), pp. 1-8.

IOC, SCOR, and IAPSO (2010). "The international thermodynamic equation of seawater-Calculation and use of thermodynamic properties," Intergovernmental Oceanographic Commission, Manuals and Guides No. 56 (UNESCO), $196 \mathrm{pp}$

Jan, S., Lien, R.-C., and Ting, C.-H. (2008). "Numerical study of baroclinic tides in Luzon Strait," J. Oceangr. 64, 789-802.

Karig, D. E. (1975). "Basin genesis in the Philippine Sea," in Initial Reports of the Deep Sea Drilling Project, 31, edited by D. E. Karig, J. C. Ingle, Jr., A. H. Bouma, C. H. Ellis, N. Haile, I. Koizumi, H. Y. Ling, I. MacGregor, J. C. Moore, H. Ujiie, T. Watanabe, S. M. White, and M. Yasui (U.S. Government Printing Office, Washington, DC), pp. 857-879.

Kerry, C. G., Powell, B. S., and Carter, G. S. (2013). "Effects of remote generation sites on model estimates of M2 internal tides in the Philippine Sea," J. Phys. Oceanogr. 43, 187-204.

Kobashi, F., and Kawamura, H. (2002). "Seasonal variation and instability nature of the North Pacific Subtropical Countercurrent and the Hawaiian Lee Countercurrent,” J. Geophys. Res. 107, 3185, doi:10.1029/ 2001JC001225.

Locarnini, R. A., Mishonov, A. V., Antonov, J. I., Boyer, T. P., and Garcia, H. E. (2006). World Ocean Atlas 2005. Temperature, edited by S. Levitus (U.S. Government Printing Office, Washington, DC), NOAA Atlas NESDIS61, Vol. 1, $182 \mathrm{pp}$

Louden, K. E. (1977). "Paleomagnetism of DSDP sediments, phase shifting of magnetic anomalies, and rotations of the West Philippine Basin," J. Geophys. Res. 82, 2989-3002, doi:10.1029/JB082i020p02989.

Matsubara, Y., and Seno, T. (1980). "Paleogeographic reconstruction of the Philippine Sea at 5 m.y. B.P.," Earth Planet. Sci. Lett. 51, 406-414.

Mercer, J. A., Colosi, J. A., Howe, B. M., Dzieciuch, M. A., Stephen, R., and Worcester, P. F. (2009). "LOAPEX: The Long-range Ocean Acoustic Propagation EXperiment," IEEE J. Ocean. Eng. 34, 1-11.

Morozov, A. K., and Webb, D. C. (2003). "A sound projector for acoustic tomography and global ocean monitoring," IEEE J. Ocean. Eng. 28, 174-185.

Morozov, A. K., and Webb, D. C. (2007). "Underwater tunable organ-pipe sound source," J. Acoust. Soc. Am. 122, 777-785.

Munk, W. H. (1981). "Internal waves and small-scale processes," in Evolution of Physical Oceanography, edited by B. A. Warren and C. Wunsch (The MIT Press, Cambridge, MA), pp. 264-291.

Munk, W. H., Worcester, P. F., and Wunsch, C. (1995). Ocean Acoustic Tomography (Cambridge University Press, Cambridge, UK), 433 pp.

Niwa, Y., and Hibiya, T. (2004). "Three-dimensional numerical simulation of $\mathrm{M}_{2}$ internal tides in the East China Sea," J. Geophys. Res. 109, C04027, doi:10.1029/2003JC001923.
Powell, B. S., Kerry, C. G., and Cornuelle, B. D. (2013). "Using a numerical model to understand the connection between the ocean and acoustic travel-time measurements," J. Acoust. Soc. Am. 134, 3211-3222.

Qiu, B. (1999). "Seasonal eddy field modulation of the North Pacific Subtropical Countercurrent: TOPEX/Poseidon observations and theory," J. Phys. Oceanogr. 29, 2471-2486.

Qiu, B., and Chen, S. (2010). "Interannual variability of the North Pacific Subtropical Countercurrent and its associated mesoscale eddy field," J. Phys. Oceanogr. 40, 213-225.

Ramp, S. R., Tang, T. Y., Duda, T. F., Lynch, J. F., Liu, A. K., Chiu, C. S., Bahr, F. L., Kim, H. R., and Yang, Y. J. (2004). "Internal solitons in the northeastern South China Sea. Part I: Sources and deep water propagation," IEEE J. Ocean. Eng. 29, 1157-1181.

Rudnick, D. L., Jan, S., Centurioni, L., Lee, C. M., Lien, R.-C., Wang, J., Lee, D.-K., Tseng, R.-S., Kim, Y. Y., and Chern, C.-S. (2011). "Seasonal and mesoscale variability of the Kuroshio near its origin," Oceanography 24, 52-63.

Salisbury, M. H., Shinohara, M., Suetsugu, D., Arisaka, M., Diekmann, B., Januszczak, N., and Savov, I. P. (2006). "Leg 195 synthesis: Site 1201-a geological and geophysical section in the West Philippine Basin from the 660-km discontinuity to the mudline," in Proceedings of the Ocean Drilling Program, Scientific Results,195, edited by M. Shinohara, M. H. Salisbury, and C. Richter (Ocean Drilling Program, College Station, TX), pp. 1-27.

Sea-Bird Electronics, Inc. (2012). "Real-time oceanography with inductive moorings and the inductive modem module," Application Note No. 92, http:// www.seabird.com/pdf_documents/ApplicationNotes/AppNote92Oct12.pdf (Last viewed April 26, 2013), 9 pp.

Seno, T., and Maruyama, S. (1984). "Paleogeographic reconstruction and origin of the Philippine Sea," Tectonophysics 102, 53-84.

Shipboard Scientific Party (1975a). "Site 290," Initial Reports of the Deep Sea Drilling Project, 31, edited by D. E. Karig, J. C. Ingle, Jr., A. H. Bouma, C. H. Ellis, N. Haile, I. Koizumi, H. Y. Ling, I. MacGregor, J. C. Moore, H. Ujiie, T. Watanabe, S. M. White, and M. Yasui (U.S. Government Printing Office, Washington, DC), pp. 25-47.

Shipboard Scientific Party (1975b). "Site 293," Initial Reports of the Deep Sea Drilling Project, 31, edited by D. E. Karig, J. C. Ingle, Jr., A. H. Bouma, C. H. Ellis, N. Haile, I. Koizumi, H. Y. Ling, I. MacGregor, J. C. Moore, H. Ujiie, T. Watanabe, S. M. White, and M. Yasui (U.S. Government Printing Office, Washington, DC), pp. 131-168.

Shipboard Scientific Party (2002). "Leg 195 summary," in Proceedings of the Ocean Drilling Program, Initial Reports, 195, edited by M. H. Salisbury, M. Shinohara, C. Richter, E. Araki, S. R. Barr, M. D'Antonio, S. M. Dean, B. Diekmann, K. M. Edwards, P. B. Fryer, P. J. Gaillot, W. S. Hammon III, D. Hart, N. Januszczak, S. C. Komor, M. B. Kristensen, J. P. Lockwood, M. J. Mottl, C. L. Moyer, K. Nakahigashi, I. P. Savov, X. Su, K.-Y. Wei, and T. Yamada (Ocean Drilling Program, College Station, TX), pp. 1-63.

Shooter, J. A., DeMary, T. E., and Wittenborn, A. F. (1990). "Depth dependence of noise resulting from ship traffic and wind,” IEEE J. Ocean. Eng. 15, 292-298.

Smith, W. H. F., and Sandwell, D. T. (1997). "Global sea floor topography from satellite altimetry and ship depth soundings," Science 277, $1956-1962$.

Stephen, R. A., Bolmer, S. T., Dzieciuch, M. A., Worcester, P. F., Andrew, R. K., Buck, L. J., Mercer, J. A., Colosi, J. A., and Howe, B. M. (2009). "Deep seafloor arrivals: An unexplained set of arrivals in long-range ocean acoustic propagation,” J. Acoust. Soc. Am. 126, 599-606.

Stephen, R. A., Bolmer, S. T., Udovydchenkov, I. A., Dzieciuch, M. A., Worcester, P. F., Andrew, R. K., Mercer, J. A., Colosi, J. A., and Howe, B. M. (2012). "Analysis of Deep Seafloor Arrivals Observed on NPAL04," WHOI Technical Report WHOI-2012-09 (Woods Hole Oceanographic Institution, Woods Hole, MA), 88 pp.

Stephen, R. A., Bolmer, S. T., Udovydchenkov, I. A., Worcester, P. F., Dzieciuch, M. A., Andrew, R. K., Mercer, J. A., Colosi, J. A., and Howe, B. M. (2013). "Deep seafloor arrivals in long range ocean acoustic propagation," J. Acoust. Soc. Am. 134, 3307-3317.

Stephen, R. A., Kemp, J. N., McPeak, S., Bolmer, S. T., Carey, S. D., Aaron, E., Campbell, R. C., Moskovitz, B., Calderwood, J., Cohen, B., Worcester, P. F., and Dzieciuch, M. A. (2011). "Ocean Bottom Seismometer Augmentation of the Philippine Sea Experiment (OBSAPS) Cruise Report," WHOI Technical Report WHOI-2011-04 (Woods Hole Oceanographic Institution, Woods Hole, MA), 183 pp. 
Van Uffelen, L. J., Nosal, E.-M., Howe, B. M., Carter, G. S., Worcester, P. F., Dzieciuch, M. A., Heaney, K. D., Campbell, R. L., and Cross, P. S. (2013). "Estimating uncertainty in subsurface glider position using transmissions from fixed acoustic tomography sources," J. Acoust. Soc. Am. 134, 3260-3271.

Van Uffelen, L. J., Worcester, P. F., Dzieciuch, M. A., and Rudnick, D. L. (2009). "The vertical structure of shadow-zone arrivals at long range in the ocean," J. Acoust. Soc. Am. 125, 3569-3588.

Van Uffelen, L. J., Worcester, P. F., Dzieciuch, M. A., Rudnick, D. L., and Colosi, J. A. (2010). "Effects of upper ocean sound-speed structure on deep acoustic shadow-zone arrivals at 500- and 1000-km range," J. Acoust. Soc. Am. 127, 2169-2181.

Webb, D. C., Morozov, A. K., and Ensign, T. H. (2002). "A new approach to low frequency wide-band projector design," in OCEANS' 02 MTS/IEEE Conference Proceedings (IEEE, New York), pp. 2342-2349.

White, A. W., Andrew, R. K., Mercer, J. A., Worcester, P. F., Dzieciuch, M. A., and Colosi, J. A. (2013). "Wavefront intensity statistics for $284-\mathrm{Hz}$ broadband transmissions to $107-\mathrm{km}$ range in the Philippine Sea: Observations and modeling," J. Acoust. Soc. Am. 134, 3347-3358.

Worcester, P. F., Carey, S., Dzieciuch, M. A., Green, L. L., Horwitt, D., Lemire, J. C., and Norenberg, M. (2009). "Distributed Vertical Line Array (DVLA) acoustic receiver," in Proc. Third Int. Conf. Underwater Acoustic Measurements, edited by J. S. Papadakis, and L. Bjørnø (Foundation for Research and Technology Hellas, Heraklion, Greece), pp. 113-118.

Worcester, P. F., and Spindel, R. C. (2005). "North Pacific Acoustic Laboratory," J. Acoust. Soc. Am. 117, 1499-1510.

Young, A. M. (1975). "An underwater acoustic source for the infrasonic and low-audio-frequency range (USRD Type J13 Transducer)," NRL Report FR-7967 (Naval Research Laboratory, Orlando, FL), 19 pp.

Zhao, Z., and D'Asaro, E. (2011). "A perfect focus of the internal tide from the Mariana Arc," Geophys. Res. Lett. 38, L14609, doi:10.1029/ 2011 GL047909. 